\title{
Application of shell spiral deviation methodology to fossil brachiopods: Implications for obtaining specimen ontogenetic ages
}

\author{
Joanna V. Clark, Anthony E. Aldridge, Matías Reolid, \\ Kazuyoshi Endo, and Alberto Pérez-Huerta
}

\begin{abstract}
Knowledge of specimen ontogenetic ages of fossil brachiopods has great utility in paleoecological and paleoclimatic studies, but there is currently no efficient means of obtaining this information. Previous studies have shown that shell spiral deviations correspond to ontogenetic ages and seasonal growth in modern brachiopods, but this approach has not been tested on fossil specimens. Here, we analyze the application of this methodology using four species of fossil brachiopods, including Laqueus rubellus, Terebratula terebratula, Platystrophia ponderosa, and Pseudoatrypa sp., each of which possesses different shell outlines and surface ornamentation patterns. The computer programs Vextractor and $\mathrm{R}$ were used for digitizing and morphometric analyses, respectively. Our results indicate that smooth biconvex shells produce spiral deviation graphs similar to those generated from modern brachiopods that yield plausible ontogenetic ages, but without providing by themselves information on seasonal growth and factors controlling shell growth.
\end{abstract}

Joanna V. Clark. Department of Geological Sciences, University of Alabama, 2003 Bevill Building, Tuscaloosa, Alabama, 35487, United States. jvclark@crimson.ua.edu Corresponding author Anthony E. Aldridge. PO Box 19576, Woolston, Christchurch, 8241, New Zealand. tony@southnet.co.nz Corresponding author

Matías Reolid. Departamento de Geología, Universidad de Jaen, Campus Las Lagunillas s/n, 23071 Jaén, Spain.mreolid@ujaen.es

Kazuyoshi Endo. Department of Earth and Planetary Sciences, The University of Tokyo, Tokyo 113-003, Japan. endo@eps.s.u-tokyo.ac.jp

Alberto Pérez-Huerta. Department of Geological Sciences, The University of Alabama, Tuscaloosa, Alabama, 35487, United States. aphuerta@ua.edu

Keywords: spiral deviations; fossil brachiopods; ontogenetic age; digitizing; R code

Submission: 4 June 2015. Acceptance: 4 November 2015

Clark, Joanna V., Aldridge, Anthony E., Reolid, Matías, Endo, Kazuyoshi, and Pérez-Huerta, Alberto. 2015. Application of shell spiral deviation methodology to fossil brachiopods: Implications for obtaining specimen ontogenetic age. Palaeontologia Electronica 18.3.54A: 1-39

palaeo-electronica.org/content/2015/1189-brachiopod-spiral-deviations 


\section{INTRODUCTION}

Knowledge of ontogenetic ages of fossil specimens is essential to many studies focused on phylogeny, life histories, and population dynamics. Within marine invertebrates, brachiopods have been intensely studied because they have a long geologic history, their shells are resistant to diagenesis, they are geographically widespread, and they have lived in a variety of marine habitats throughout the Phanerozoic (e.g., Brand et al., 2011; Ivany, 2012; Pérez-Huerta et al., 2014). Brachiopod shells also demonstrate morphologies reflecting ontogeny throughout their lives, as do other invertebrates secreting a shell, and thus, it is important to consider ontogenetic ages and variations during ontogeny when making taxonomic descriptions because of the implications on phylogeny and evolutionary patterns (e.g., Beecher, 1893; Balthasar, 2004; Pérez-Huerta, 2004). Furthermore, life history of an organism is another area of research that requires the knowledge of specimen ontogenetic age, and many of these studies investigate how organisms change their life habits throughout ontogeny (e.g., Tomašových et al., 2008). Finally, population dynamics require the knowledge of specimen ontogenetic age; for example, brachiopod ontogenetic age has been used to determine the effect of current-sorting on the ontogenetic age frequencies in fossil assemblages (e.g., Boucot, 1953; Boucot et al., 1958).

Brachiopods have also been particularly useful in reconstructing past ecosystems and climatic conditions because they precipitate calcite shells in oxygen isotopic equilibrium with ambient seawater, and these shells are very resistant to diagenesis (e.g., Carpenter and Lohmann, 1995; Geldern et al., 2006; Suan et al., 2008; Yamamoto et al., 2010; Brand et al., 2013). Thus, studies have been conducted to investigate the effectiveness of brachiopod shells as paleoclimate indicators at different stages during their ontogeny (e.g., Buening and Spero, 1996; Yamamoto et al., 2010; Kercher and Carlson, 2012). Additionally, studies that relate shell morphology to seasonal growth and specimen ontogenetic age have the potential to provide a record of seasonality throughout geologic history (Pérez-Huerta et al., 2014; Butler et al., 2015).

Despite numerous studies using brachiopods in paleoecology and as bioarchives for paleoclimate reconstructions, obtaining an accurate and efficient method of determining specimen ontogenetic age in fossil specimens is elusive. Modern brachiopod ontogenetic ages and growth rates have been studied based on in situ shell measure- ments from living brachiopods (Terebratalia transversa and Terebratulina retusa), although these studies are sparse (e.g., Thayer, 1977; Curry, 1982). Approaches using a combination of shell chemistry and growth lines have been used to determine growth rates of modern specimens, (Barbin and Gaspard, 1995; Yamamoto et al., 2010), but both of these techniques have associated problems (e.g., interpretation of growth lines) that limit their effectiveness (see Pérez-Huerta et al., 2014 and references therein).

Most recently, shell spiral deviations have been used to determine ontogenetic ages of modern brachiopods, where deviations of the shell outline from a perfect logarithmic spiral represent changes in growth (Aldridge and Gaspard, 2011 and references therein). A perfect logarithmic spiral is a shape that maintains the same rate of vertical to anterior growth and has been shown to resemble the growth patterns of organisms that grow their shells by accretion (see Aldridge, 1998 and references therein). Thus, logarithmic spirals have been used to precisely describe the shape of shells with accretionary growth (e.g., Aldridge, 1998, Pérez-Huerta et al., 2014). Although spiral deviations have been observed in modern brachiopods and linked to ontogenetic age and seasonal growth, it has not yet been shown to be fully effective in the study of fossil specimens (Angiolini et al., 2012). In this study, fossil brachiopods, ranging in age from the Ordovician to the Pleistocene, are analyzed to determine whether shell spiral deviations are similar to those observed in modern brachiopods and are potentially useful in specimen ontogenetic age determination. The main focus of this study is the R-based spiral deviation methodology for determining ontogenetic ages in fossil brachiopods. Discussion of problems inherent to this methodology and related to different shell morphologies of fossil specimens is included.

\section{MATERIALS AND METHODS}

\section{Sample Information}

The studied specimens are well-preserved shells of four species of fossil brachiopods, Laqueus rubellus (Family Laqueidae), Terebratula terebratula (Family Terebratulidae), Platystrophia ponderosa (Family Plectorthidae), and Pseudoatrypa sp. (Family Atrypidae) (Figure 1). Shell parameters (length, width, and thickness) and spiral deviations (Table 1) were determined for three specimens of each species, with larger specimens selectively chosen to maximize the shell growth 

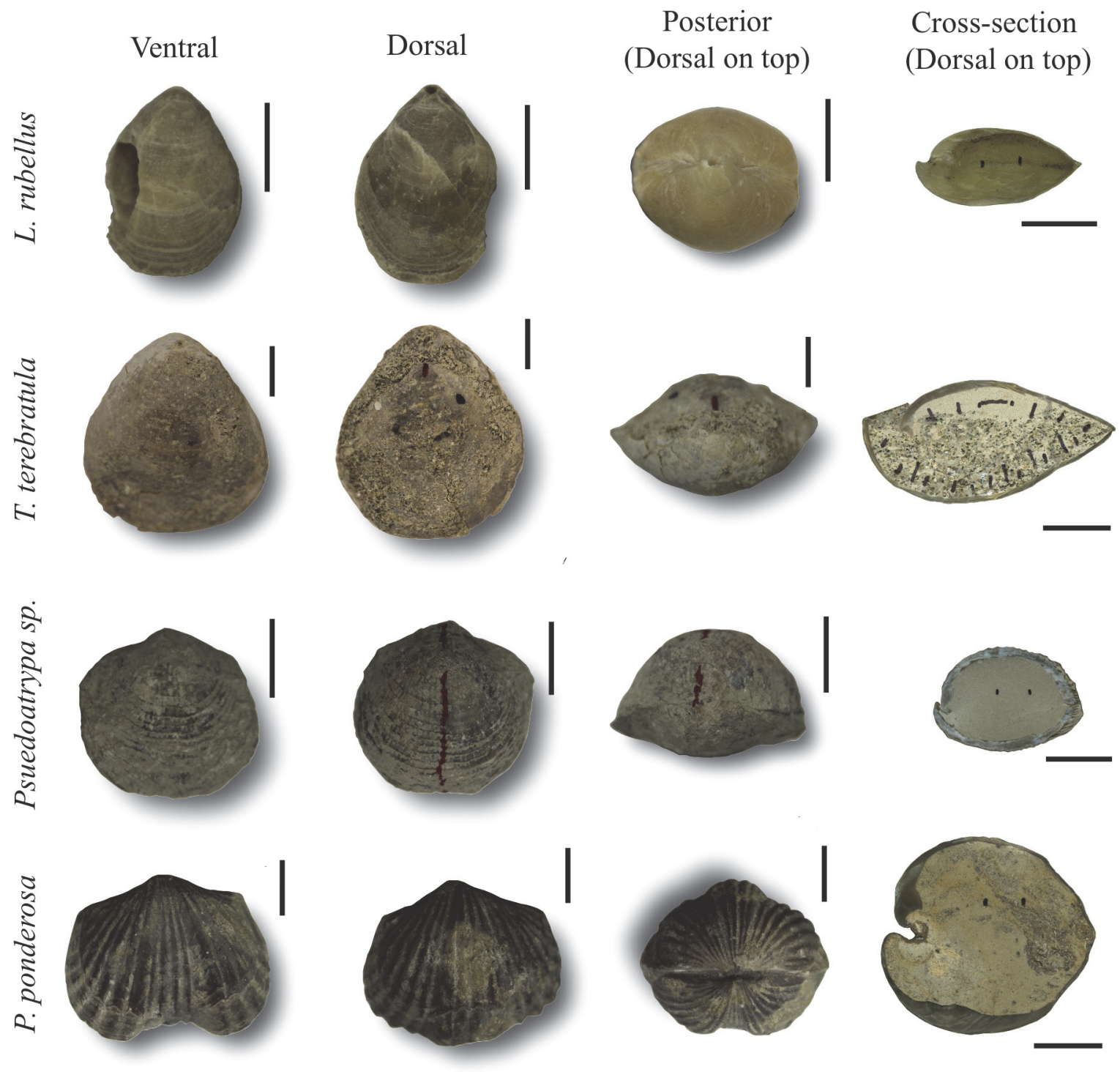

FIGURE 1. Ventral, dorsal, posterior, and longitudinal-sectional views of the fossil brachiopods Laqueus rubellus, Terebratula terebratula, Pseudoatrypa sp., and Platystrophia ponderosa. Scale bars equal $1 \mathrm{~cm}$.

record (see Pérez-Huerta et al., 2014). All four species possessed biconvex shells without ornamentations, such as spines, but shells with ribs and growth lamellae are included (Figure 1). In addition to the four species analyzed, the ventral valve of a strophomenid brachiopod, Rafinesquina sp., was analyzed for its spiral deviations to determine if they could be detected in shells with flatter convexities.

Laqueus rubellus (Sowerby, 1846). Shells of Laqueus (Figure 1) were collected from the Jizodo Formation (0.39 Ma) and the Yabu Formation (0.31 $\mathrm{Ma})$ of the Shimosa Group in central Japan. The length of these shells ranges from 23.2 to 29.3 $\mathrm{mm}$. The depositional environment of specimen collection is representative of a shallow embayment, known as the paleo-Tokyo Bay. More specifically, the Jizodo Formation contains facies associated to littoral and sub-littoral zones (Endo, 1987). Original bilateral symmetry in these specimens is preserved, suggesting that these units are not tectonically deformed (Figure 1). Additionally, previous studies of this unit do not suggest significant tectonic deformation (Endo, 1987). Fossil specimens of this species were selected as a "control group" because equivalent modern individuals can be collected from the Sagami Bay at water depths between 70 to $90 \mathrm{~m}$ and have been used to 
TABLE 1. Size measurements (length, width, and thickness) and spiral deviations from all analyzed specimens of the species Laqueus rubellus, Terebratula terebratula, Platystrophia ponderosa, and Pseudoatrypa sp.

\begin{tabular}{lccccccc}
\multicolumn{1}{c}{ Specimen } & $\begin{array}{c}\text { Length } \\
(\mathbf{m m})\end{array}$ & Width $(\mathbf{m m})$ & $\begin{array}{c}\text { Thickness } \\
(\mathbf{m m})\end{array}$ & $\begin{array}{c}\text { Dorsal } \\
\text { minima }\end{array}$ & $\begin{array}{c}\text { Dorsal } \\
\text { maxima }\end{array}$ & $\begin{array}{c}\text { Ventral } \\
\text { minima }\end{array}$ & $\begin{array}{c}\text { Ventral } \\
\text { maxima }\end{array}$ \\
L. rubellus 1 & 23.2 & 14.8 & 10.5 & 4 & 4 & 4 & 4 \\
L. rubellus 2 & 29.3 & 19.0 & 17.0 & 2 & 3 & 3 & 3 \\
L. rubellus 3 & 27.1 & 18.0 & 14.0 & 2 & 3 & 2 & 3 \\
T. terebratula 1 & 47.3 & 34.0 & 24.5 & 5 & 6 & 3 & 4 \\
T. terebratula 2 & 38.7 & 34.2 & 18.9 & 4 & 3 & 4 & 4 \\
T. terebratula 3 & 40.4 & 32.0 & 21.9 & 4 & 4 & 3 & 4 \\
P. ponderosa 1 & 23.9 & 35.0 & 22.5 & 2 & 3 & 2 & 2 \\
P. ponderosa 2 & 35.5 & 46.0 & 28.0 & 3 & 4 & 4 & 4 \\
P. ponderosa 3 & 26.0 & 32.4 & 26.0 & 4 & 5 & 3 & 4 \\
Pseudoatrypa sp. 1 & 19.0 & 18.0 & 10.0 & N/A & N/A & N/A & N/A \\
Pseudoatrypa sp. 2 & 21.0 & 22.0 & 16.1 & N/A & N/A & N/A & N/A \\
Pseudoatrypa sp. 3 & 19.5 & 19.6 & 11.7 & N/A & N/A & N/A & N/A
\end{tabular}

determine shell spiral deviations (Pérez-Huerta et al., 2014).

Terebratula terebratula (Linnaeus, 1758). Shells ranging from 38.7 to $47.3 \mathrm{~mm}$ in length (Figure 1) were collected from Tortonian (Upper Miocene) deposits of the Guadix Basin, a Neogene intramountain basin located in southern Spain. They correspond to accumulations in prodelta facies with an inferred depth around $30 \mathrm{~m}$ (see more details in Reolid et al., 2012). Original bilateral symmetry in these specimens is preserved, suggesting that these units are not tectonically deformed (Figure 1). Additionally, tectonic deformation was not reported in previous descriptions of this unit (Reolid et al., 2012).

Pseudoatrypa sp. Shells ranging from 19.0 to $21.0 \mathrm{~mm}$ in length (Figure 1) are Early Devonian in age and were sampled from an active quarry in Parson, Tennessee. Samples were collected from the Ross Formation, which has been interpreted to represent a shallow marine shelf depositional environment, below normal wave base but above storm wave base (Rigby and Clement, 1995). Original bilateral symmetry in these specimens is preserved, suggesting that these units are not tectonically deformed (Figure 1). Additionally, the literature reference for this unit does not suggest significant tectonic deformation.

Platystrophia ponderosa (King, 1850). Shells ranging from 23.9 to $35.5 \mathrm{~mm}$ in length (Figure 1) are Late Ordovician in age and were collected from the Arnheim Formation in southwestern Ohio. This formation is representative of a shallow sub-tidal depositional environment (Holland, 2013). Original bilateral symmetry in these specimens is preserved, suggesting that these units are not tectonically deformed (Figure 1). Additionally, the literature reference for this unit does not suggest significant tectonic deformation.

Rafinesquina sp. Specimen is Late Ordovician in age and was sampled from the Leipers Formation of the Maysville Group in south-central Tennessee. The lower Leipers Formation has been interpreted as a lagoon depositional environment (Wahlman, 1992). Original bilateral symmetry in these specimens is preserved, suggesting that these units are not tectonically deformed. Additionally, the literature reference for this unit does not suggest significant tectonic deformation.

\section{Sample Preparation}

Samples were brushed off with Kim-Wipes to ensure that there was minimal unconsolidated material adhered onto the outside of the shells. Any non-shell material on the shell surface can make digitizing the shell outline difficult because it becomes unclear where the edge of the shell is located. Shells were then embedded in epoxy resin and cut with a Buehler Isomet 1000 Precision Saw along the plane of symmetry, producing two identical halves (Figure 2). The shell surface of each half was ground and polished with aluminum oxide (grit size $=1.0$ and $0.3 \mu \mathrm{m}$ ) until the surface was flat and free of scratches.

\section{Digitizing}

A $5 \mathrm{~mm}$ scale was drawn onto the non-shell portion of the cross section of each shell (Figure 3 ). Both halves of each shell were then scanned into a computer, producing high-resolution TIFF images of shell cross-sections. These images were edited in Adobe Photoshop, with dorsal valves on top and curved in a counter-clockwise direction from the umbo. The edited images were then imported into the image digitization software called Vextractor 


\section{Platystrophia ponderosa}
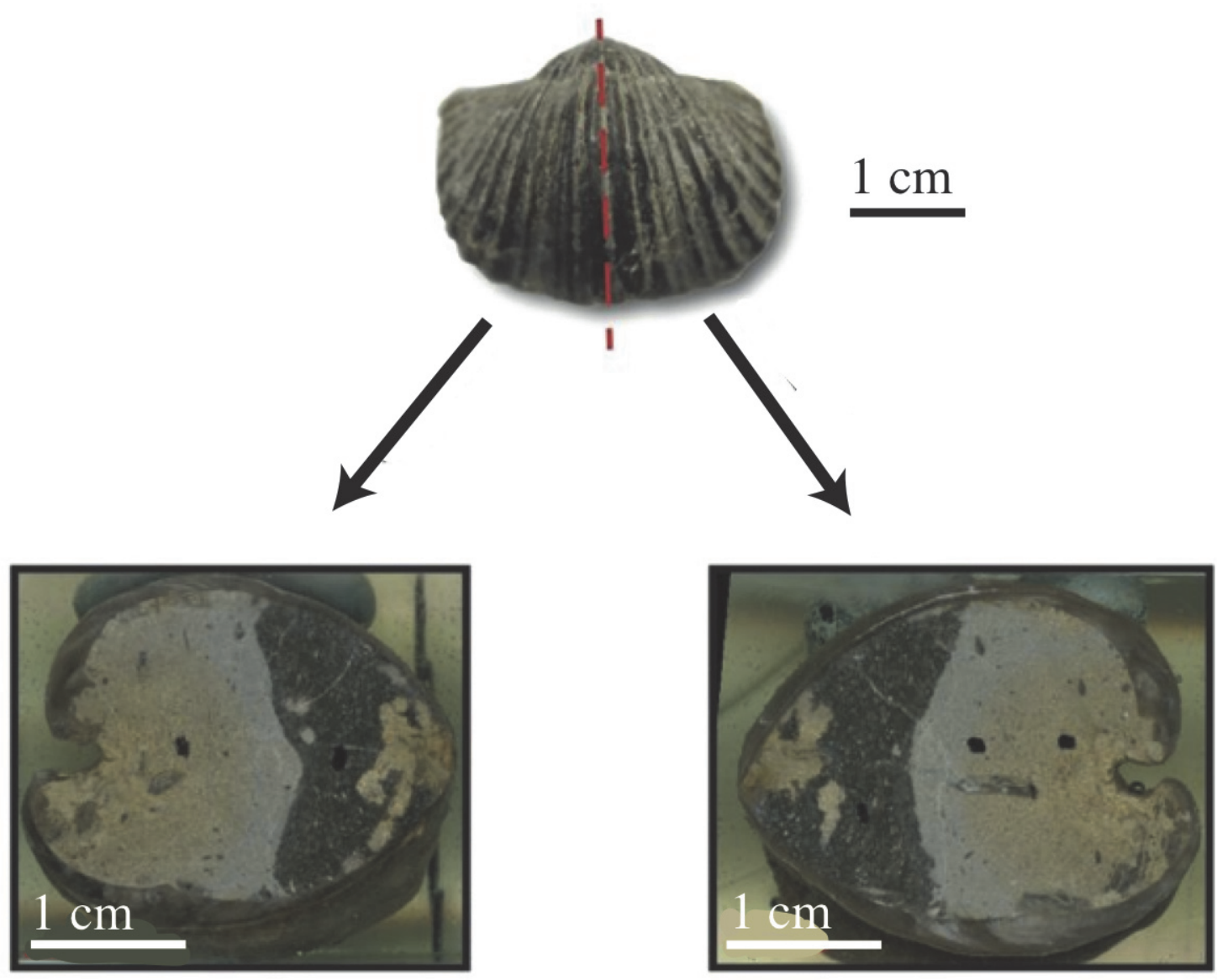

FIGURE 2. Example of a shell sample (Platystrophia ponderosa) sectioning through the plane of symmetry, producing two identical halves. Both halves were analyzed for their spiral deviations.

(Version 6.31; VextraSoft Vladivostok, Russia; available at www.vextrasoft.com).

It is important to digitize only one valve at a time so that each valve has its own set of $(x, y)$ coordinates that can be analyzed separately for spiral deviations. Before digitizing, the scale that was drawn on the cross-section was used to create reference coordinates on the digital image (Figure 3 ). The shell was digitized with a polyline tool by clicking the edge of the shell surface, at $<0.1 \mathrm{~mm}$ intervals, from the umbo to anterior shell regions. After the valve was digitized, the outline was selected and the vector was saved in ASCII format as a $x y z$ file. The $x y z$ file was then opened and saved as a Microsoft Excel file for future use.

\section{Spiral Deviations}

The coordinates for each specimen were imported into a free, downloadable computer program called R (Version 3.0.2; R Core Team, 2013), which is oftentimes used in biology and statistics (e.g., Zuur et al., 2009; Aldridge and Gaspard, 2011). These coordinates were used with $R$ code previously developed (see Aldridge and Gaspard, 2011; Appendices 1-4) to produce biological outlines as well as spiral deviation graphs (Figure 3).

Each shell has a spiral deviation graph for both the dorsal and ventral valves of each half (Figures 4-7; Appendix 5). It is important that the coordinates, saved in Microsoft Excel files, be imported and analyzed separately. The basic procedure of creating spiral deviation graphs is as follows, and it is described in more detail in the appendices. The $x$ and $y$ coordinates are defined as objects in $R$ 


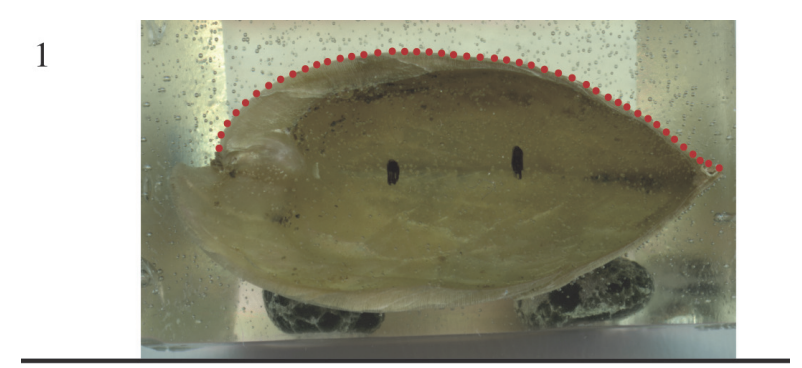

2

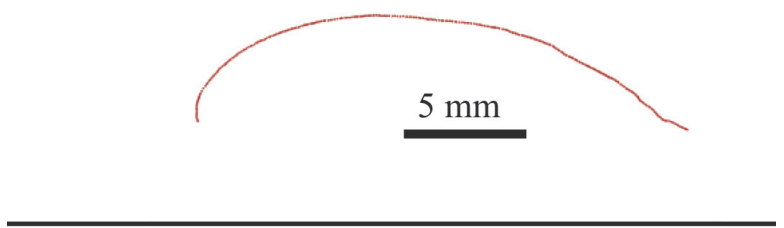

3

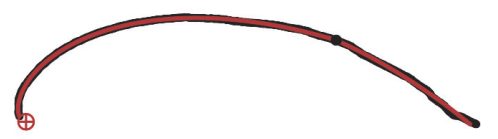

4

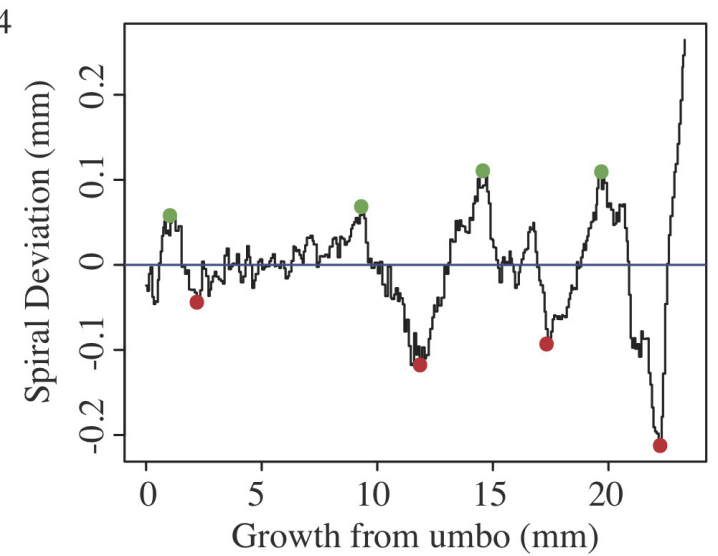

FIGURE 3. Example of shell (Laqueus rubellus) digitization and spiral fitting. 1, The brachiopod shell was digitized by clicking the outline in an anterior-ward direction, starting at the umbo. 2, The digitized outline was saved as $(x, y)$ coordinates, which were used to plot a biological outline in R. 3, R code was used to fit a perfect logarithmic spiral to the shell outline. 4, The deviations from a perfect spiral were represented in a spiral deviation graph, with green points representing spiral maxima and red points representing spiral minima.

(Appendix 1). A biological outline of a valve is created (Appendix 2). The spiral deviation code is entered into $R$ (Appendix 3). A spiral axis location is manually chosen. $R$ estimates the best spiral axis location based on the initial location that is chosen manually (Appendix 4). Code is used to plot spiral deviations versus growth from umbo (Appendix 4).

\section{RESULTS}

Specimens of Laqueus rubellus, Terebratula terebratula, and Platystrophia ponderosa produced spiral deviations patterns that were wide and large in magnitude (Figures 4-6), while specimens of Pseudoatrypa sp. produced spiral deviations patterns that were large in amplitude, and frequent or very narrow in width (Figure 7 ). Shells of Laqueus rubellus produced between two and four spiral maxima and minima per valve (Figure 4 and Table 1 ), between three and six spiral maxima and minima per valve for shells of Terebratula terebratula (Figure 5 and Table 1), and between two and five spiral maxima and minima per valve for shells of Platystrophia ponderosa (Figure 6 and Table 1). In contrast to these species, specimens of Pseudoatrypa sp. produced many spiral deviations, resulting in numerous potential maxima and minima for both valves. Finally, it was impossible to fit a perfect spiral to the ventral valve of one specimen of Rafinesquina sp. because of its flat shape.

\section{DISCUSSION}

\section{Which Shells Produce Annual Spiral Deviations?}

Biconvex shells without ornamentation, such as ribs and spines, as in the case of Laqueus rubellus and Terebratula terebratula, produced shell spiral deviations that were wide and large in magnitude, and similar to those described for modern brachiopod shells with biological significance (Aldridge and Gaspard, 2011; Pérez-Huerta et al., 2014). Pseudoatypa sp. displayed numerous shell spiral deviations that were narrow and large in magnitude, but these were caused by the combination of lateral ribs and growth lamellae, which produce noises masking any signals representing ontogenetic growth patterns (Figures 7 and 8). Platystrophia ponderosa produced shell spiral deviations that were wide and large in magnitude, despite the presence of prominent ribs aligned along the anterior-posterior direction. When using shells that possess ribs aligned along the anteriorposterior direction or shells with a fold and sulcus, it is important to section the shell straight along the plane of symmetry. Cutting off the plane of symmetry or through ribs can produce spiral deviations that appear to have no biological significance. Because spiral deviations can be on the order of 

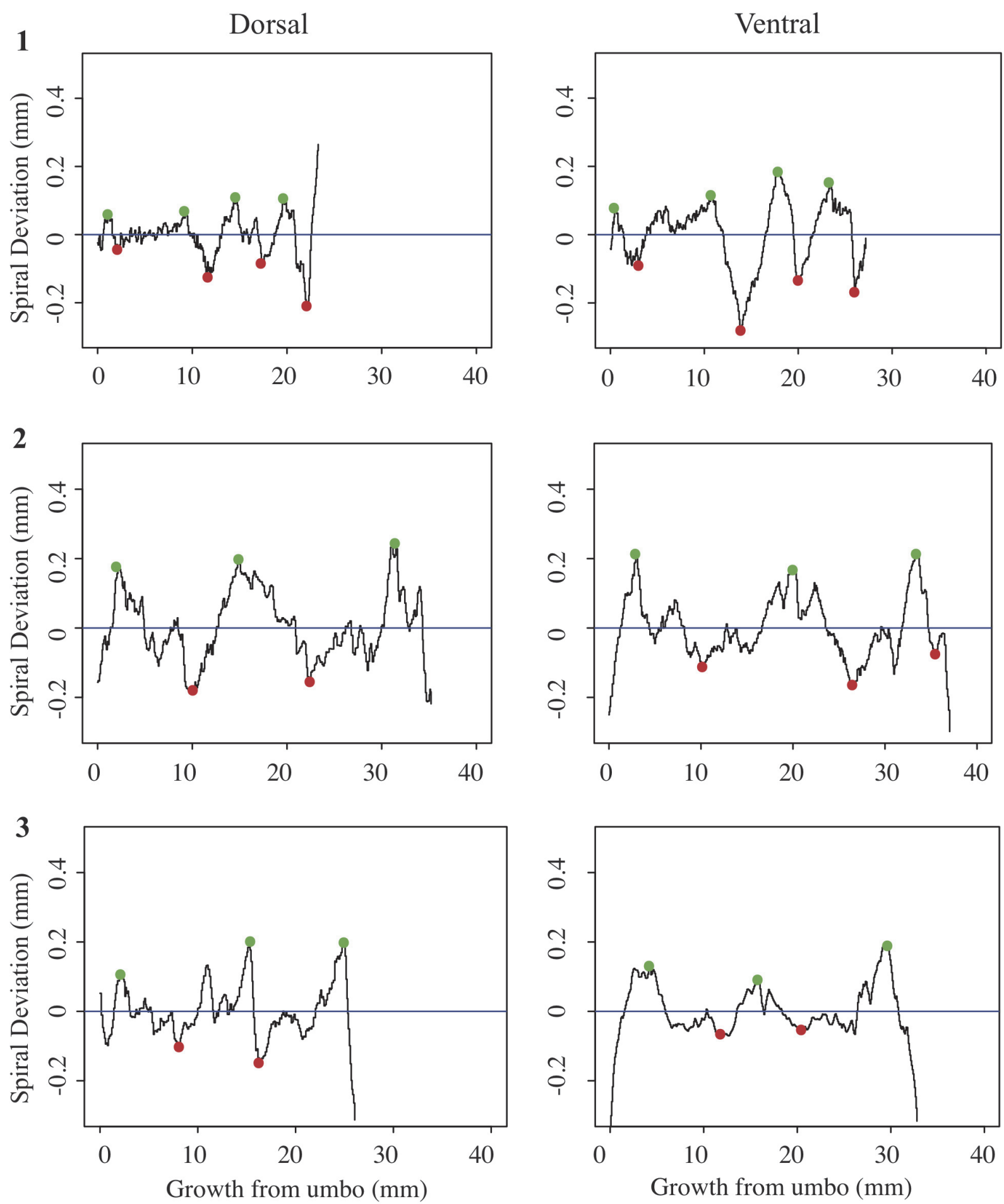

FIGURE 4. Spiral deviations from the dorsal and ventral valves of specimens one (1), two (2), and three (3) of the species Laqueus rubellus. 
1

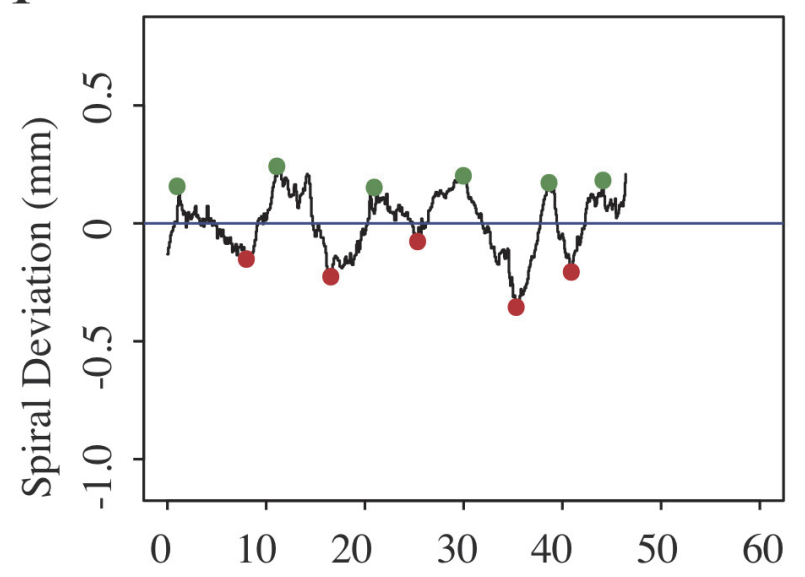

2

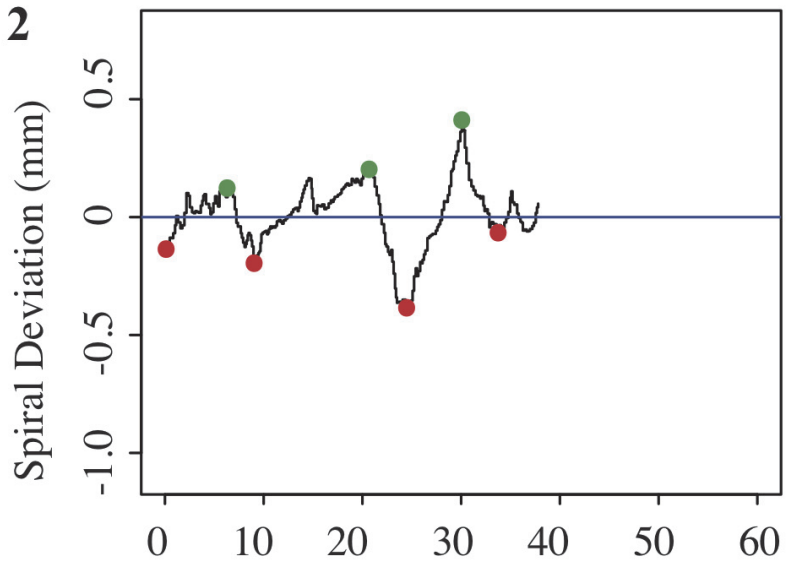

3

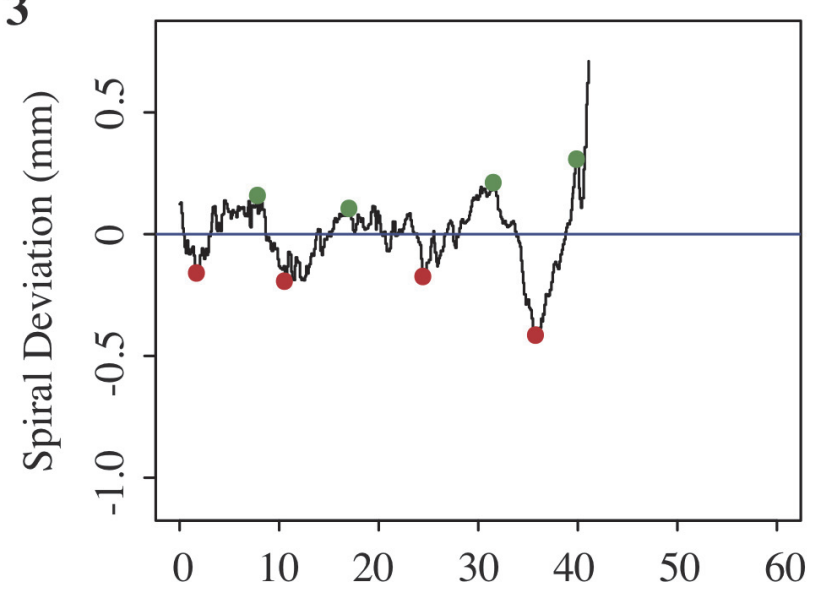

Growth from umbo (mm)
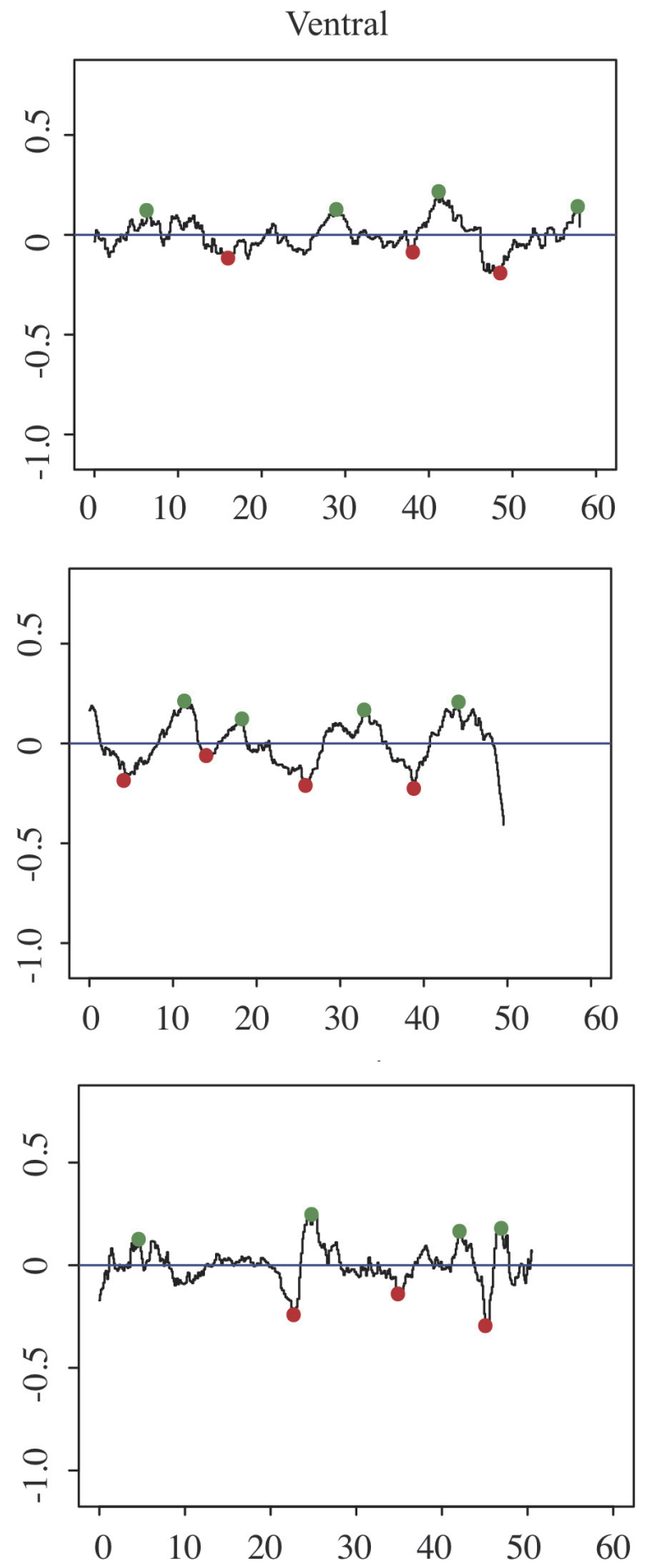

Growth from umbo (mm)

FIGURE 5. Spiral deviations from three specimens of the species Terebratula terebratula. 

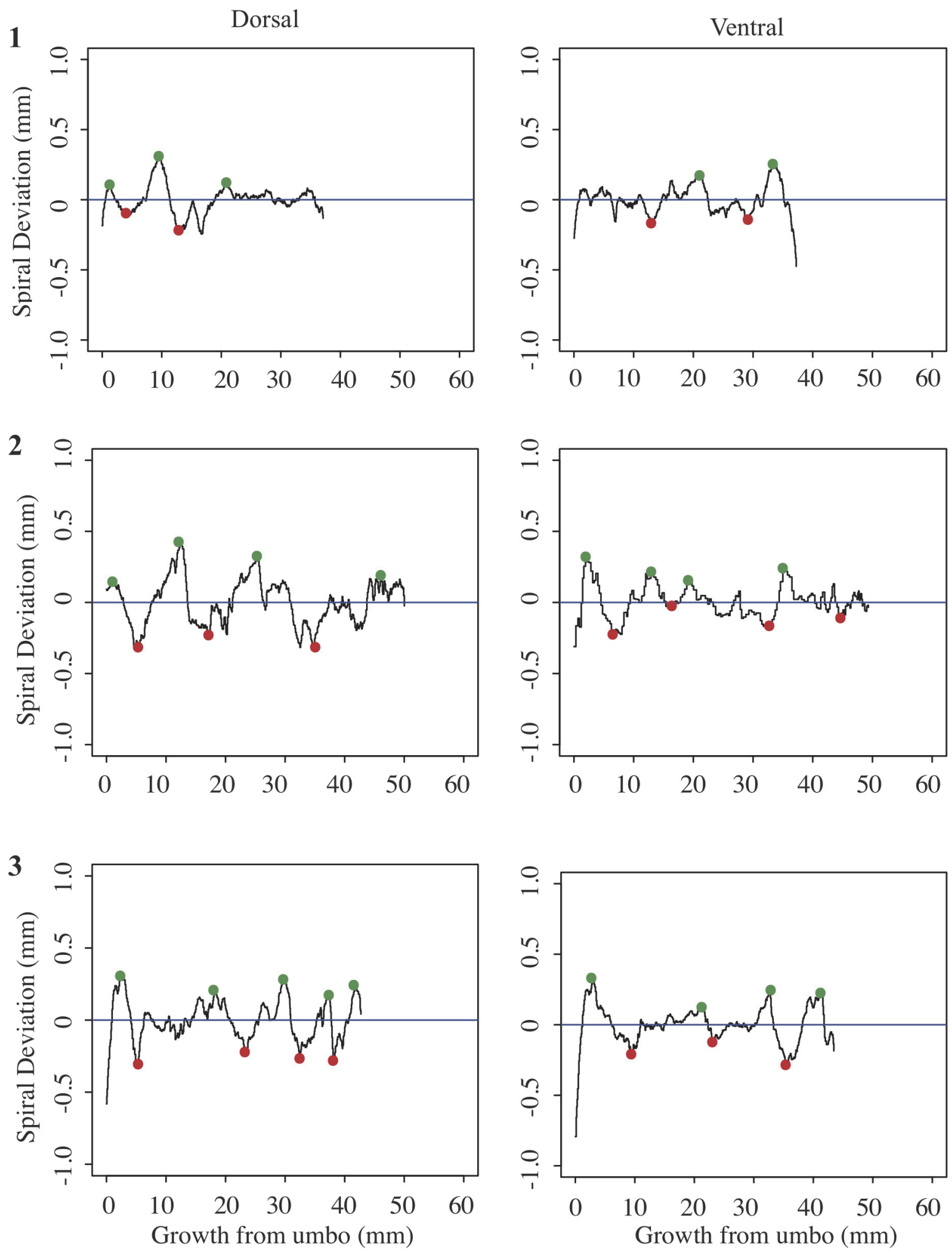

FIGURE 6. Spiral deviations from three specimens of the species Platystrophia ponderosa. 

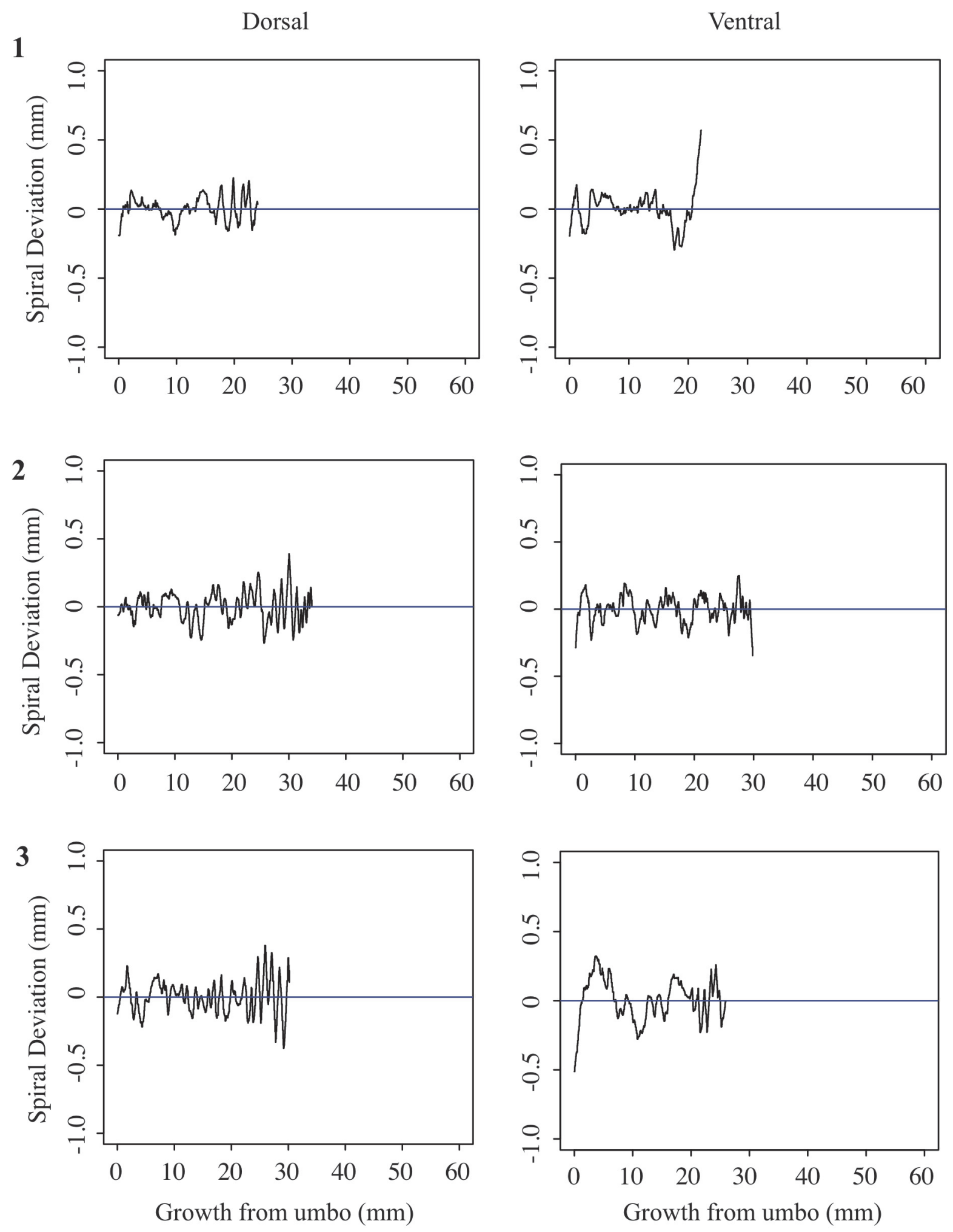

FIGURE 7. Spiral deviations from three specimens of the species Pseudoatrypa sp. 

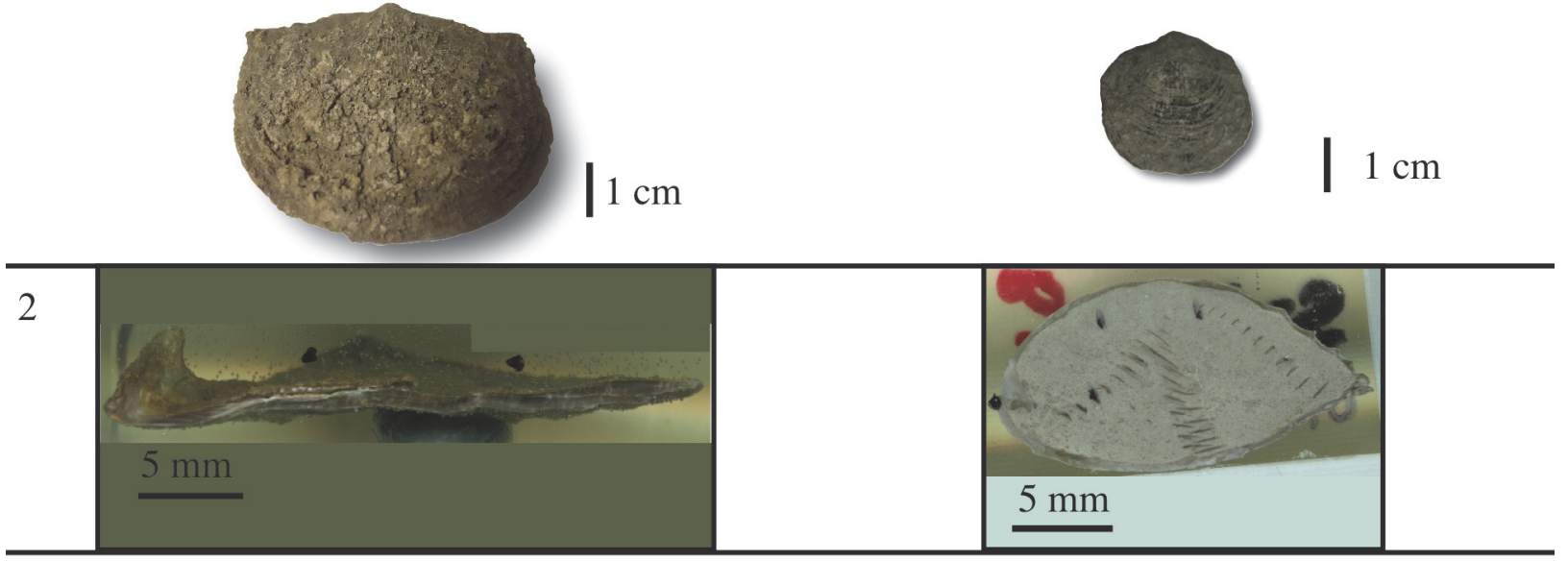

3
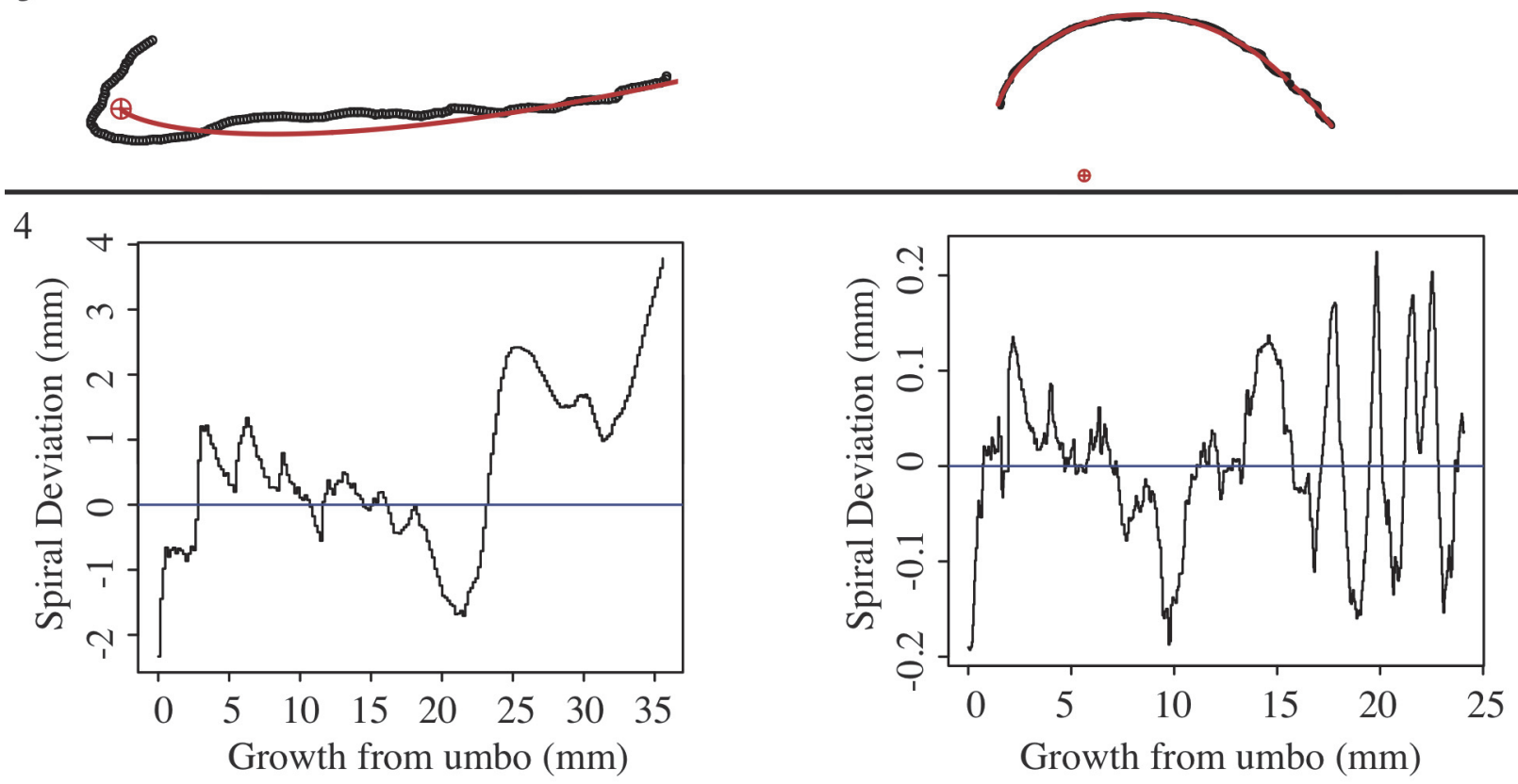

FIGURE 8. Example of two fossil brachiopod species, Rafinesquina sp. (left) and Pseudoatrypa sp. (right), which generated problematic spiral deviation graphs. 1, Ventral view 2, Longitudinal-sectional view 3, Spiral fitting 4, Spiral deviations graphs.

$0.1 \mathrm{~mm}$ in magnitude, the use of shells with a fold and sulcus or ribs can result in spiral deviations that are not due to ontogenetic growth if sample preparation is not precise. Therefore, shells without any ornamentation present the best potential for determining specimen ontogenetic age based on spiral deviations.

In addition to the work in selected species, a spiral deviations graph was generated from the ventral valve of a strophomenid brachiopod (Rafinesquina sp.) to determine if spiral deviations could be detected on shells with minimal ornamentation but flatter valves (Figure 8). It was impossible to fit a spiral to this shell because of its flat shape, and therefore it could not be used to determine a specimen ontogenetic age. Overall, biconvex shells are the best target of study for ontogenetic age determination using the present methodology.

\section{Is It Necessary to Fit More Than One Spiral?}

In some shells, the rate of anterior to vertical growth changes throughout the individual's life- 


\section{Terebratula terebratula}
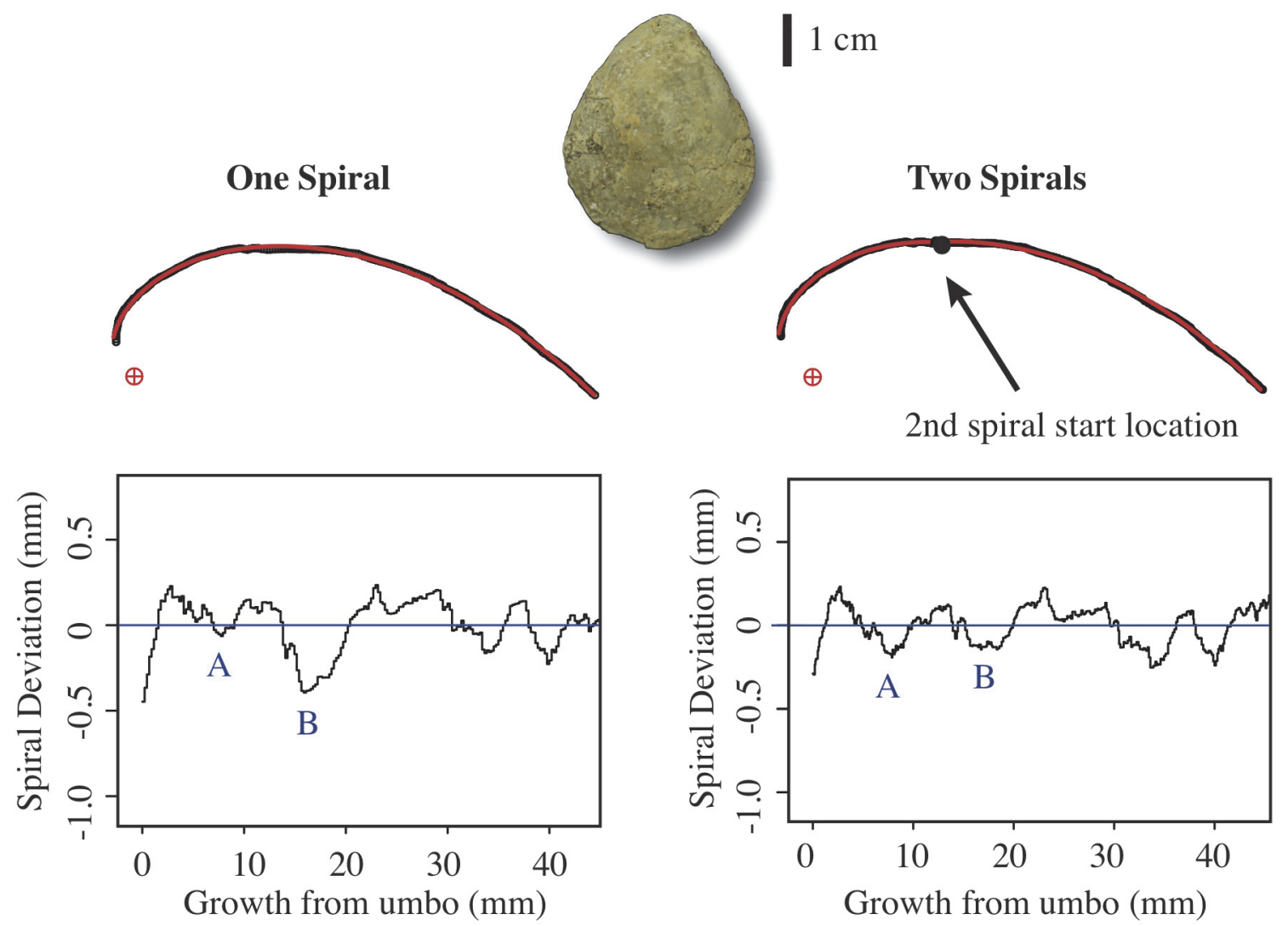

FIGURE 9. Comparison of spiral deviation graphs when the dorsal valve of Terebratula terebratula specimen is fit to one (left) and two (right) spirals. A and B represent locations on the graphs that change drastically when two spirals are fit to the biological outline instead of one. Minimum $A$ becomes more distinct when two spirals are used whereas the opposite occurs for minimum B.

time. A valve may be very rounded towards the umbo but flatter towards the anterior region. Abrupt changes in valve convexity have been observed in modern brachiopod species including Laqueus rubellus, where valve convexity changes from circular to ovular at maturity (Endo, 1987). Therefore, a spiral that fits the posterior region of the shell may not fit the anterior region of the shell. When one spiral is fit to an outline that experiences an abrupt change in growth, there will be a defined "M" shape in the spiral deviation graph that is due to a poor spiral fitting rather than to seasonal growth episodes (Figure 9). To solve the problem of poor spiral fitting, two or more spirals have to be fitted to the shell using the $R$ code that we designed (Appendix 4). In this analysis, fitting two spirals to the shells instead of one resulted in a reduction in spiral fitting error (Figure 9), meaning that the spirals more closely fitted the outlines and any resulting deviations were more likely to have biological significance (Tables 2-5).

Selecting a location where the second spiral starts is a user-involved process. The shell outline is composed of coordinates from the digitizing process, and every set of $(x, y)$ coordinates has a point number. The point number " 1 " is the point closest to the umbo and higher numbers are closer to the anterior region of the shell. To find a spiral change location, the point number of the location where the shell shape changes has to be determined. Once an approximate location is determined, a spiral deviation graph is generated using this point number as the second spiral start location. If the "M" shape has been reduced, the spiral matches the biological outline better. Thus, the spiral fitting error has been reduced and the deviations are more likely to have biological significance (Figure 9). 
TABLE 2. Spiral output from three specimens of the species Laqueus rubellus. Maximum length is the maximum distance from the posterior to anterior region. Arc length is the maximum distance along the outline of the valve, from the posterior to anterior regions. Spiral axis (a) is the distance between the spiral axis and the first set of coordinates at the umbo. Spiral parameter $(k)$ indicates the shape of the valve, where higher numbers represent flatter valves. Two spirals were fit to these shells, thus there were two spiral axes and parameters. Error is an indicator of how well the spirals fit the biological outline. The error from one spiral fitting was included as a comparison. $\mathrm{N}$ is the number of digitized points on the biological outline.

\begin{tabular}{|c|c|c|c|c|c|c|c|c|c|}
\hline Specimen & $\begin{array}{c}\text { Length } \\
(\mathrm{mm})\end{array}$ & $\begin{array}{c}\text { Arc- } \\
\text { length } \\
(\mathrm{mm})\end{array}$ & a1 & a2 & $\begin{array}{l}\text { k1 parameter } \\
\text { (spiral angle) }\end{array}$ & $\begin{array}{l}\text { k2 parameter } \\
\text { (spiral angle) }\end{array}$ & $\begin{array}{c}\text { Error: } \\
\text { two } \\
\text { spirals } \\
(\mathrm{mm})\end{array}$ & $\begin{array}{l}\text { Error: } \\
\text { one } \\
\text { spiral } \\
(\mathrm{mm})\end{array}$ & $\mathbf{N}$ \\
\hline 1 Dorsal & 19.96 & 23.30 & 0.40 & 0.95 & $1.63\left(31.5^{\circ}\right)$ & $1.24\left(38.9^{\circ}\right)$ & 0.06 & 0.13 & 312 \\
\hline 1 Ventral & 23.23 & 29.62 & 0.99 & 2.76 & $1.20\left(39.8^{\circ}\right)$ & $0.79\left(51.6^{\circ}\right)$ & 0.13 & 0.20 & 289 \\
\hline 2 Dorsal & 25.78 & 35.21 & 27.03 & 22.51 & $0.57\left(60.3^{\circ}\right)$ & $0.01\left(89.2^{\circ}\right)$ & 0.25 & 0.32 & 385 \\
\hline 2 Ventral & 29.28 & 37.03 & 5.17 & 9.76 & $0.77\left(52.3^{\circ}\right)$ & $0.45\left(65.6^{\circ}\right)$ & 0.09 & 0.19 & 373 \\
\hline 3 Dorsal & 20.47 & 26.05 & 0.95 & 1.50 & $1.08\left(42.7^{\circ}\right)$ & $0.91\left(47.7^{\circ}\right)$ & 0.08 & 0.11 & 258 \\
\hline 3 Ventral & 27.14 & 32.79 & 7.29 & 4.78 & $0.40\left(68.4^{\circ}\right)$ & $0.67\left(56.2^{\circ}\right)$ & 0.08 & 0.15 & 400 \\
\hline
\end{tabular}

TABLE 3. Spiral output from three specimens of the species Terebratula terebratula (see caption for Table 2 for definitions and abbreviations).

\begin{tabular}{|l|c|c|c|c|c|c|c|c|c|}
\hline Specimen & $\begin{array}{c}\text { Length } \\
(\mathbf{m m})\end{array}$ & $\begin{array}{c}\text { Arc- } \\
\text { length } \\
\mathbf{( m m )}\end{array}$ & a1 & a2 & $\begin{array}{c}\text { k1 parameter } \\
\text { (spiral angle) }\end{array}$ & $\begin{array}{c}\text { k2 parameter } \\
\text { (spiral angle) }\end{array}$ & $\begin{array}{c}\text { Error: } \\
\text { two } \\
\text { spirals } \\
\text { (mm) }\end{array}$ & $\begin{array}{c}\text { Error: } \\
\text { one } \\
\text { spiral } \\
(\mathbf{m m})\end{array}$ & $\begin{array}{c}\mathbf{N} \\
\text { (mm }\end{array}$ \\
\hline 1 Dorsal & 39.25 & 46.41 & 1.84 & 2.70 & $1.40\left(35.5^{\circ}\right)$ & $1.19\left(40.1^{\circ}\right)$ & 0.12 & 0.15 & 514 \\
V Dontral & 47.25 & 58.04 & 5.60 & 6.68 & $0.93\left(47.0^{\circ}\right)$ & $0.82\left(50.8^{\circ}\right)$ & 0.08 & 0.10 & 343 \\
2 Ventral & 33.17 & 37.80 & 3.52 & 1.51 & $1.05\left(43.5^{\circ}\right)$ & $1.51\left(33.5^{\circ}\right)$ & 0.14 & 0.30 & 247 \\
3 Dorsal & 38.69 & 49.52 & 5.28 & 2.47 & $0.66\left(56.5^{\circ}\right)$ & $0.97\left(45.8^{\circ}\right)$ & 0.11 & 0.29 & 459 \\
3 Ventral & 34.47 & 41.09 & 2.08 & 0.89 & $-1.11\left(-42.0^{\circ}\right)$ & $-1.52\left(-33.4^{\circ}\right)$ & 0.14 & 0.21 & 355 \\
\end{tabular}

\section{What Are Valid Criteria to Select Annual Spiral Deviations?}

Determining quantitative criteria to define spiral deviations is problematic because growth rates are affected by many factors other than inter-species variation. Even within the same species, growth rates can vary because of individual genetics and health, degree of attachment, among others. Although growth rates vary from specimen to specimen, brachiopod growth rates tend to decrease with increasing ontogenetic age (e.g., Thayer, 1977; Endo, 1987). This trend has been demonstrated in many species of modern brachiopods (e.g., Terebratalia transversa), and has been observed in the spiral deviation graphs of some, but not all, of the specimens analyzed in this study (e.g., Figure 4.1 and Figure 6.3). In this study, quantitative criteria were set as to what defined spiral maxima and minima, but it is important to remember that there is a qualitative component to spiral deviation analysis because growth rates vary within the same species and tend to decrease with increasing ontogenetic age, as shown by the anal- ysis of the dorsal and ventral valves of three specimens of each taxon (Figures 4-7).

Previous work showed that spiral deviations greater than $0.025 \mathrm{~mm}$ in magnitude represented seasonal growth on the dorsal valves of fully matured, modern specimens of Laqueus rubellus (see Pérez-Huerta et al., 2014). In this study, deviations were interpreted as growth episodes if they were $0.05 \mathrm{~mm}$ above or below zero. These criteria yielded ontogenetic ages between three and four years (young adult specimens), and possessed length and width measurements that agree with growth rate analyses by Yamamoto et al. (2010). Specimens two and three had similar maximum lengths, and spiral deviation analyses showed that both specimens were approximately three years old at death (Table 1). These specimens were approximately one to two years younger than predicted by Yamamoto et al. (2010), based on their maximum lengths. Specimen one had a slightly smaller maximum length and yielded an ontogenetic age of four years, which strongly agreed with the growth rate analysis by Yamamoto et al. (2010). These slight differences are most likely the result of differing growth rates of individuals within 
TABLE 4. Spiral output from three specimens of the species Platystrophia ponderosa (see caption for Table 2 for definitions and abbreviations).

\begin{tabular}{|c|c|c|c|c|c|c|c|c|c|}
\hline $\begin{array}{c}\text { Specimen } \\
\text { (No./valve) }\end{array}$ & $\begin{array}{c}\text { Length } \\
(\mathrm{mm})\end{array}$ & $\begin{array}{c}\text { Arc- } \\
\text { length } \\
(\mathrm{mm})\end{array}$ & a1 & a2 & $\begin{array}{l}\text { k1 parameter } \\
\text { (spiral angle) }\end{array}$ & $\begin{array}{l}\text { k2 parameter } \\
\text { (spiral angle) }\end{array}$ & $\begin{array}{l}\text { Error: } \\
\text { two } \\
\text { spirals } \\
\text { (mm) }\end{array}$ & $\begin{array}{l}\text { Error: } \\
\text { one } \\
\text { spiral } \\
(\mathrm{mm})\end{array}$ & $\mathbf{N}$ \\
\hline 1 Dorsal & 23.52 & 37.09 & 3.15 & 3.65 & $0.70\left(55.1^{\circ}\right)$ & $0.53\left(62.2^{\circ}\right)$ & 0.09 & 0.10 & 514 \\
\hline 1 Ventral & 23.86 & 37.23 & 1.41 & 2.35 & $0.80\left(51.5^{\circ}\right)$ & $0.63\left(57.7^{\circ}\right)$ & 0.11 & 0.16 & 492 \\
\hline 2 Dorsal & 33.65 & 50.02 & 2.75 & 3.81 & $0.94\left(46.9^{\circ}\right)$ & $0.67\left(56.1^{\circ}\right)$ & 0.14 & 0.16 & 484 \\
\hline 2 Ventral & 35.49 & 49.32 & 2.01 & 3.31 & $0.89\left(48.4^{\circ}\right)$ & $0.72\left(54.1^{\circ}\right)$ & 0.11 & 0.17 & 187 \\
\hline 3 Dorsal & 24.69 & 42.73 & 4.66 & 3.18 & $-0.45\left(-65.7^{\circ}\right)$ & $-0.59\left(-59.7^{\circ}\right)$ & 0.27 & 0.29 & 524 \\
\hline 3 Ventral & 25.97 & 43.45 & 5.02 & 8.91 & $0.51\left(62.8^{\circ}\right)^{\prime}$ & $0.29\left(74.0^{\circ}\right)$ & 0.14 & 0.21 & 490 \\
\hline
\end{tabular}

TABLE 5. Spiral output from three specimens of the species Pseudoatrypa sp. (see caption for Table 2 for definitions and abbreviations).

\begin{tabular}{|l|c|c|c|c|c|c|c|c|c|}
\hline $\begin{array}{c}\text { Specimen } \\
\text { (No./valve) }\end{array}$ & $\begin{array}{c}\text { Length } \\
(\mathbf{m m})\end{array}$ & $\begin{array}{c}\text { Arc- } \\
\text { length } \\
\mathbf{( m m )}\end{array}$ & $\mathbf{a 1}$ & $\mathbf{a 2}$ & $\begin{array}{c}\text { k1 parameter } \\
\text { (spiral angle) }\end{array}$ & $\begin{array}{c}\text { k2 parameter } \\
\text { (spiral angle) }\end{array}$ & $\begin{array}{c}\text { Error: } \\
\text { two } \\
\text { spirals } \\
(\mathbf{m m})\end{array}$ & $\begin{array}{c}\text { Error: } \\
\text { one } \\
\mathbf{s p i r a l} \\
(\mathbf{m m})\end{array}$ & $\begin{array}{c}\mathbf{N} \\
\mathbf{( m m}\end{array}$ \\
\hline 1 Dorsal & 18.60 & 24.07 & 4.58 & 6.27 & $-0.50\left(-63.4^{\circ}\right)$ & $-0.35\left(-71.0^{\circ}\right)$ & 0.08 & 0.10 & 474 \\
1 Ventral & 19.02 & 22.18 & 8.43 & 9.63 & $1.65\left(31.3^{\circ}\right)$ & $0.50\left(63.4^{\circ}\right)$ & 0.13 & 0.16 & 438 \\
2 Dorsal & 20.52 & 34.03 & 5.30 & 9.26 & $0.39\left(68.6^{\circ}\right)$ & $0.17\left(80.1^{\circ}\right)$ & 0.11 & 0.15 & 628 \\
2 Ventral & 21.03 & 29.82 & 16.34 & 17.65 & $0.10\left(84.0^{\circ}\right)$ & $-0.34\left(-71.1^{\circ}\right)$ & 0.10 & 0.16 & 557 \\
3 Dorsal & 19.38 & 30.17 & 3.30 & 9.32 & $0.69\left(55.5^{\circ}\right)$ & $0.23\left(76.9^{\circ}\right)$ & 0.12 & 0.22 & 497 \\
3 Ventral & 19.54 & 25.94 & 10.88 & 23.04 & $0.37\left(69.5^{\circ}\right)$ & $-0.18\left(-79.6^{\circ}\right)$ & 0.15 & 0.22 & 419 \\
\hline
\end{tabular}

the same species, reinforcing the idea that there is not a unique growth rate for a given brachiopod taxon (Pérez-Huerta et al., 2014).

Thayer (1977) studied growth rates of the extant brachiopod Terebratalia transversa throughout ontogeny. His study found that the average growth rate for individuals less than $10 \mathrm{~mm}$ in length was approximately $3.6 \mathrm{~mm} /$ year and the average growth rate for individuals greater than 10 $\mathrm{mm}$ was approximately $1.5 \mathrm{~mm} /$ year. This study, as well as the spiral deviation study by Pérez-Huerta et al. (2014), was taken into account when choosing spiral maxima and minima for the species Terebratula terebratula, because there are no growth rate studies for this extinct species. Spiral deviations had to be $0.1 \mathrm{~mm}$ above or below zero to be considered a seasonal growth episode. Resulting ontogenetic ages ranged from three to approximately five years (Table 1), which appears to be reasonable because the abundance of specimens over the age of five is less than $1 \%$ in other species of modern terebratulid brachiopods (e.g., Curry, 1982).

Ontogenetic studies of modern rhynchonellid brachiopods, which are phylogenetically related to the extinct species Platystrophia ponderosa, are less abundant and conclusive than for terebratulid taxa. Therefore, the same criteria that were used to define spiral deviations for Terebratula terebratula were used for $P$. ponderosa because of their similar sizes. The three specimens of $P$. ponderosa produced ontogenetic ages between 3 and 5 years, which appear plausible based on their relative sizes (Table 1).

The spiral deviation methodology applied to fossil brachiopod taxa produces encouraging results to determining ontogenetic growth and accurate specimen ontogenetic age estimates based on a comparison of growth in modern species. However, in order to better define criteria for what are actually meaningful spiral maxima and minima, high-resolution chemical analyses should be done at locations of spiral deviations to determine a correspondence to periodical environmental parameters (e.g., seawater temperatures; Buening and Spero, 1996; Yamamoto et al., 2010; Pérez-Huerta et al., 2014; Butler et al., 2015).

\section{CONCLUSIONS}

The methodology of shell spiral deviation applied to fossil brachiopods has great potential for utility in determining specimen ontogenetic ages, which has significant implications for the use of brachiopods in paleoclimatic and paleoecological studies (i.e., determining paleoseasonality). Our findings show that spiral deviations can be obtained for fossil taxa (Laqueus rubellus, Terebratula terebratula, and Platystrophia ponderosa), 
yielding specimen ontogenetic ages that agree with previous growth rate studies in similar modern taxa and are plausible based on relative shell measurements. In contrast, results indicate the problems of using this methodology with shells that have complex ornamentation patterns (Pseudoatrypa sp.) or without biconvex shells (Rafinesquina sp.). Also, a refinement of the methodology as well as analyzing more shells within a wider ontogenetic sampling dataset is needed to define more objective criteria to detect "true" or "significant" maxima and minima deviations. Furthermore, the method can determine specimen ontogenetic ages assuming that the spiral deviations chosen are due to seasonal growth. Thus, conducting a chemical analysis at locations of spiral deviations on the shell outline would help confirm the criteria for deviations that are due to seasonal growth episodes.

\section{ACKNOWLEDGMENTS}

This research was partially funded by the University of Alabama Graduate Student Travel Fund, the DGS Hook's Fund, and the Johnson Travel Fund. S. Ebersole (Alabama Geological Survey) is thanked for facilitating specimens of $P$. ponderosa and R. Keyes for providing specimens of Pseudoatrypa sp. and Rafinesquina sp.

\section{REFERENCES}

Aldridge, A.E. 1998. Brachiopod outline and the importance of the logarithmic spiral. Paleobiology, 24: 215226.

Aldridge, A.E. and Gaspard, D. 2011. Brachiopod life histories from spiral deviations in shell shape and microstructural signature-preliminary report. Memoirs of the Association of Australian Palaeontologists, 41:257-268.

Angiolini, L., Stephenson, M., Leng, M.J., Jadoul, F., Millward, D., Aldridge, A., Andrews, J., Chenery, S., and Williams, G. 2012. Heterogeneity, cyclicity and diagenesis in a Mississippian brachiopod shell of palaeoequatorial Britain. Terra Nova, 24:16-26.

Balthasar, U. 2004. Shell structure, ontogeny and affinities of the Lower Cambrian bivalve problematic fossil Michwitzia muralensis Walcott, 1913. Lethaia, 27:381-400.

Barbin, V. and Gaspard, D. 1995. Cathodoluminescence of recent articulate brachiopod shells: Implications for growth stages and diagenesis evaluation. Geobios (Special Memoir), 18:39-45.

Beecher, C.E. 1893. Some correlation of ontogeny and phylogeny in the brachiopoda. The American Naturalist, 27:599-604.

Boucot, A.J. 1953. Life and death assemblages among fossils. American Journal of Science, 251:25-40.
Boucot, A.J., Brace, W., and Demar, R. 1958. Distribution of brachiopod of pelecypod shells by currents. Journal of Sedimentary Petrology, 28:321-332.

Brand, U., Azmy, K., Bitner, M.A., Logan, A., Zuschin, M., Came, R., and Ruggiero, E. 2013. Oxygen isotopes and $\mathrm{MgCO}_{3}$ in brachiopod calcite and a new paleotemperature equation. Chemical Geology, 359:23-31.

Brand, U., Logan, A., Bitner, M.A., Griesshaber, E., Azmy, K., and Buhl, D. 2011. What is the ideal proxy for Palaeozoic seawater chemistry? Memoirs of the Association of Australasian Palaeontologists, 41:924.

Buening, N. and Spero, H.J. 1996. Oxygen and carbonisotope analyses of the articulate brachiopod Laqueus californianus: a recorder of environmental changes in the subeuphotic zone. Marine Biology, 127:105-114.

Butler, S., Bailey, T., Lear, C., Curry, G., Cherns, L., and McDonalad, I. 2015. The Mg/Ca-temperature relationship in brachiopod shells: calibrating a potential paleoseasonality proxy. Chemical Geology, 397:106117.

Carpenter, S.J. and Lohmann, K.C. 1995. $\delta^{18} \mathrm{O}$ and $\delta^{13} \mathrm{C}$ values of modern brachiopod shells. Geochimica et Cosmochimica Acta, 59:3749-3764.

Curry, G. 1982. Ecology and population-structure of the recent brachiopod Terebratulina retusa from Scotland. Palaeontology, 25:227-246.

Endo, K. 1987. Life habit and relative growth of some Laqueid brachiopods from Japan. Transactions and Proceeding of the Palaeontological Society of Japan, 147:180-194.

Geldern. R., Joachimski, M.M., Day, J., Jansen, U., Alvarez, F., Yolkin, E.A., and Ma X. 2006. Carbon, oxygen and strontium isotope records of Devonian brachiopod shell calcite. Palaeogeography, Palaeoclimatology, Palaeoecology, 240:47-67.

Holland, S. 2013. Lithostratigraphic Glossary, retrieved March 2014. UGA Stratigraphy Lab. http:// strata.uga.edu/cincy/strata/LithostratGlossary.html

Ivany, L. 2012. Reconstructing paleoseasonality from accretionary skeletal carbonates- challenges and opportunities. The Paleontological Society Papers, 18:133-165.

Kercher, P. and Carlson, S. 2012. Recent terebratulide brachiopods: Do they faithfully record oceanographic conditions throughout ontogeny?, Abstract \#B21C0376 presented at 2012 Fall Meeting, American Geophysical Union, 3-7 December, San Francisco (USA).

King, W. 1850. A monograph of the Permian fossils of England. Palaeontographical Society, London, England.

Linnaeus, C. 1758. Systema Naturae per Regna Tria Naturae, Secundum Classes, Ordines, Genera, Species, cum Characteribus, Differentiis, Synonymis, Locis. Lugduni Batavorum, Leiden.

Pérez-Huerta, A. 2004. New carboniferous brachiopods from the eastern great basin, Nevada, USA: implica- 
tions for loop ontogeny and evolution in late Palaeozoic terebratuloids. Palaeontology, 47:1519-1537.

Pérez-Huerta, A., Aldridge, A.E., Endo, K., and Jeffries, T. E. 2014. Brachiopod shell spiral deviations (SSD): Implications for trace element proxies. Chemical Geology, 374-375:13-24.

R Core Team. 2015. R: A language and environment for statistical computing. R Foundation for Statistical Computing, Vienna, Austria. http://www.R-project.org/.

Reolid, M., García-García, F., Tomašových, A., and Soria, J. 2012. Thick brachiopod shell concentrations from prodelta and siliciclastic ramp in a Tortonian Atlantic- Mediterranean strait (Miocene, Guadix Basin, southern Spain). Facies, 58:549-571.

Rigby, J.K. and Clement, C.R. 1995. Demosponges and hexactinellid sponges from the Lower Devonian Ross Formation of West-Central Tennessee. Journal of Paleontology, 69:211-232.

Sowerby, G.B. 1846. Description of Tertiary fossil shells from South America, p. 249-264. In Darwin, C.R. (ed.), Geological observations on South America. Smith, Elder and Co., Cornhill.

Suan, G., Mattioli, E., Pittet, B., and Lecuyer, C. 2008. Evidence for major environmental perturbation prior to and during the Toarcian (Early Jurassic) oceanic anoxic event from the Lusitanian Basin, Portugal. Paleoceanography, 23:PA1202.

Thayer, C. 1977. Recruitment, Growth, and Mortality of a Living Brachiopod, with Implications for the Interpretation of Survivorship Curves. Paleobiology, 3:98109.

Tomašových, A., Carlson, S., and Labarbera, M. 2008. Ontogenetic niche shift in the brachiopod Terebratalia transversa: relationship between the loss of rotation ability and allometric growth. Palaeontology, 51:1471-1496.

Wahlman, G. 1992. Middle and upper Ordovician symmetrical univalved mollusks (Monoplacophora and Bellerophontina) of the Cincinnati Arch region. United State Government Printing Office, Washington.

Yamamoto, K., Asami, R., and Iryu, Y. 2010. Carbon and oxygen isotopic compositions of modern brachiopod shells from a warm-temperature shelf environment, Sagami Bay, central Japan. Palaeogeography, Palaeoclimatology, Palaeoecology, 291:348-359.

Zuur, A., leno, E., Walker, N., Saveliev, A., and Smith, G. 2009. Mixed effect models and extensions in ecology with $R$. Springer science and business media, New York. 


\section{APPENDIX 1.}

Instructions on inputting data into R using example coordinates from the outline of a brachiopod dorsal valve.

The following set of data shows input of coordinates into $R$ using the scan command. Copy between \#\#START and \#\#END, paste into your R command, and hit enter. The objects " $x$ " and " $y$ " are the coordinates of successive points along a biological outline. In the case of accretionary growth, coordinates are assumed to begin at the umbo and be oriented in a counter-clockwise direction. It is important that each valve or outline has its own separate coordinates. $\mathrm{R}$ interprets instructions line by line with any text after a hash symbol being ignored by $\mathrm{R}$ and serving as a comment.

Example data from a brachiopod dorsal valve. This data input method uses the scan command, which is ideal when $\mathrm{x}$ and $\mathrm{y}$ coordinates are saved in Excel or a similar program.

1. \#\#START

$\mathrm{x}<-\operatorname{scan}()$

\#\#END

2. After setting up the scan command, values are assigned to the object. Copy the following $x$ values and paste into $R$. If you have your own data saved in an Excel spreadsheet, copy the $\mathrm{x}$ value column and paste into $\mathrm{R}$.

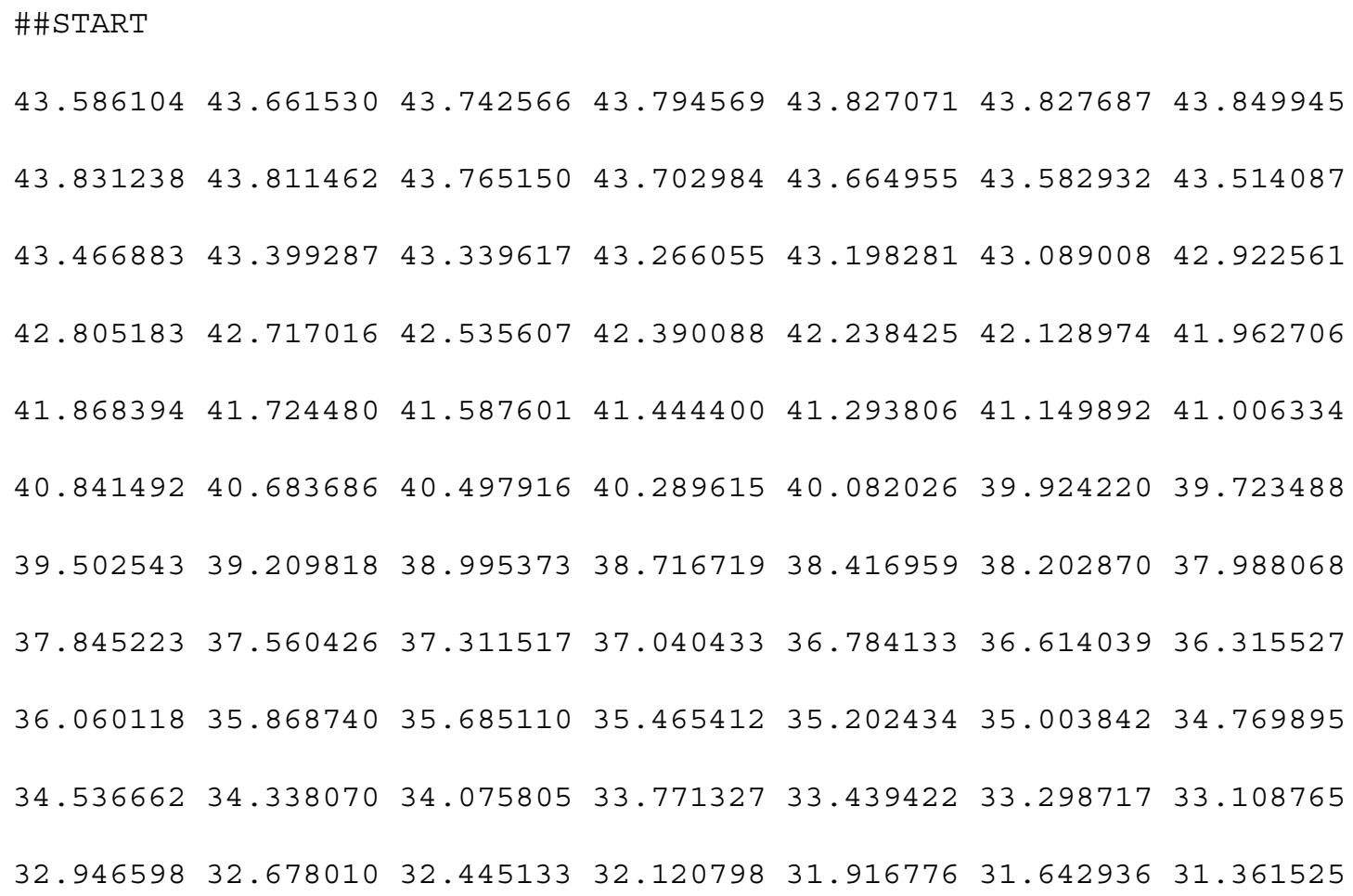




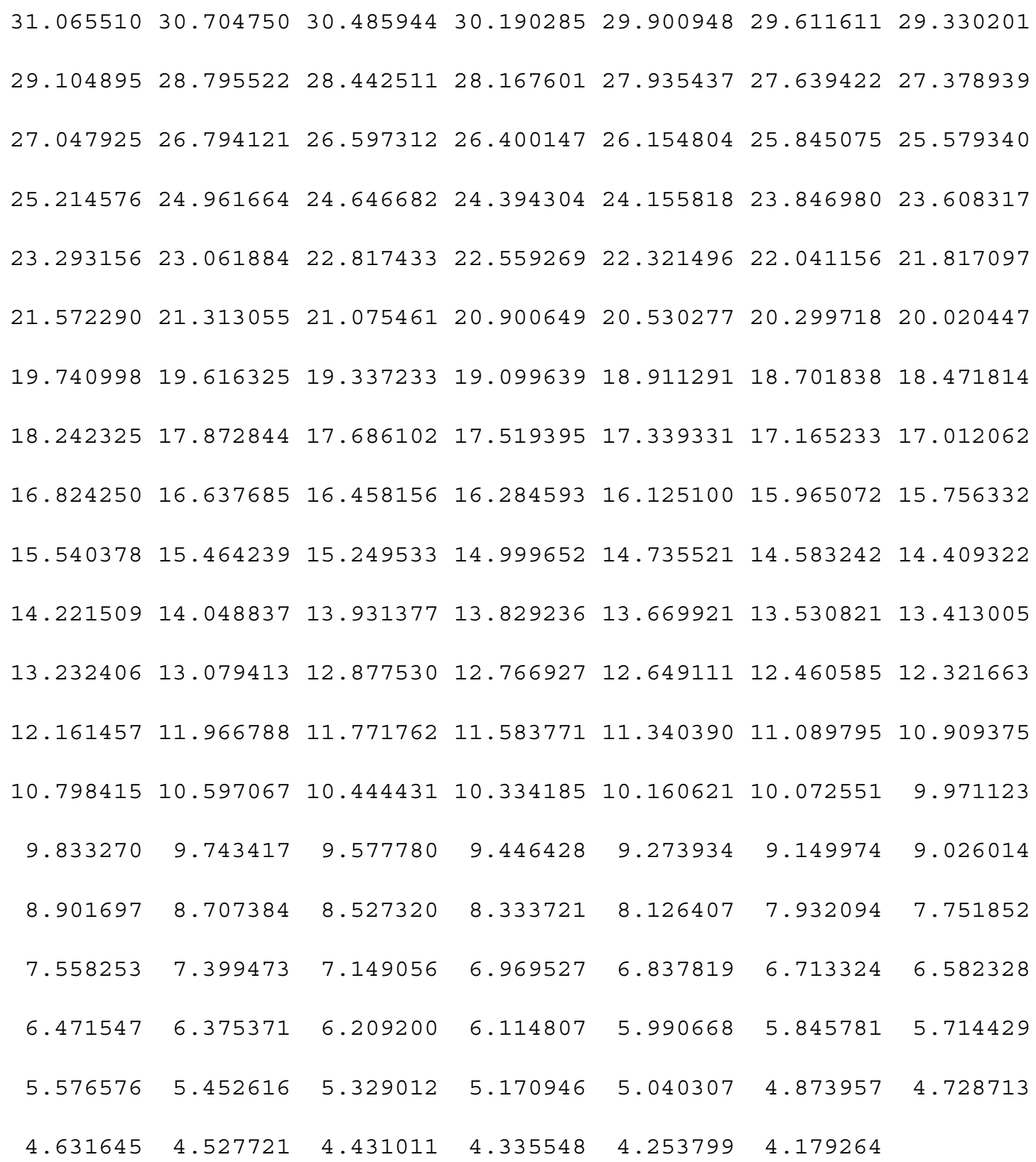

\#\#END of $\mathrm{x}$ coordinates.

- It is important to press enter twice after pasting values in order to complete the scan command.

\section{3. \#\#START}

$y<-\operatorname{scan}()$

\#\#END 
4. Copy the following $y$ values and paste into $R$. Be sure to hit enter twice after pasting the values in order to complete the scan command. Confirm that the number of values assigned to " $x$ " and " $y$ " are identical. If these numbers are different, a mistake was likely made when copying and pasting values into R.

\#\# START

$17.42193 \quad 17.50128 \quad 17.63709 \quad 17.80736 \quad 17.91378 \quad 18.16723 \quad 18.40010 \quad 18.58266$

$18.80744 \quad 18.96818 \quad 19.19891 \quad 19.31059 \quad 19.49154 \quad 19.70803 \quad 19.90395 \quad 20.07119$

$20.20343 \quad 20.32828 \quad 20.50256 \quad 20.64763 \quad 20.82644 \quad 21.01354 \quad 21.15914 \quad 21.37278$

$21.55916 \quad 21.71020 \quad 21.86230 \quad 22.03408 \quad 22.14432 \quad 22.2673922 .39064 \quad 22.48557$

$22.59439 \quad 22.71746 \quad 22.82645 \quad 22.94195 \quad 23.05763 \quad 23.16556 \quad 23.32923 \quad 23.46477$

$23.58045 \quad 23.72319 \quad 23.83023 \quad 23.99177 \quad 24.12009 \quad 24.28198 \quad 24.44334 \quad 24.55759$

$24.69998 \quad 24.78084 \quad 24.90737 \quad 25.00666 \quad 25.14763 \quad 25.26081 \quad 25.30578 \quad 25.41789$

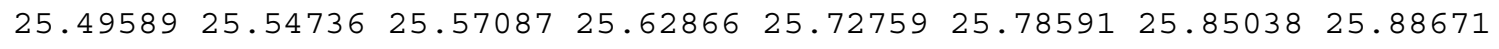

$25.94503 \quad 26.01582 \quad 26.08555 \quad 26.12641 \quad 26.12285 \quad 26.11803 \quad 26.12800 \quad 26.17047$

$26.19273 \quad 26.21267 \quad 26.20750 \quad 26.17944 \quad 26.17231 \quad 26.18593 \quad 26.25422 \quad 26.27683$

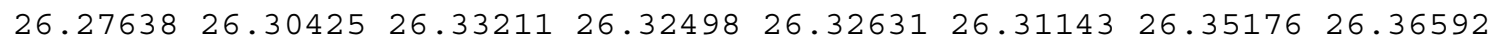

$26.36003 \quad 26.37365 \quad 26.37409 \quad 26.37978 \quad 26.39447 \quad 26.38244 \quad 26.38448 \quad 26.34306$

$26.34226 \quad 26.27216 \quad 26.22068 \quad 26.20019 \quad 26.12885 \quad 26.08725 \quad 26.05305 \quad 26.01706$

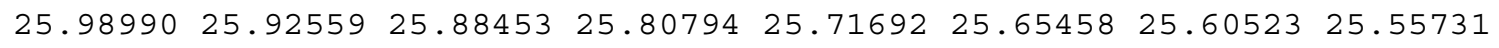

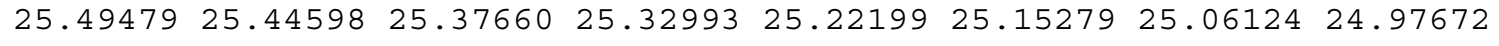

$24.89612 \quad 24.79753 \quad 24.72815 \quad 24.66002 \quad 24.59135 \quad 24.50105 \quad 24.38963 \quad 24.24651$

$24.11507 \quad 24.02636 \quad 23.90916 \quad 23.83435 \quad 23.76711 \quad 23.67788 \quad 23.5393923 .40109$

$23.30517 \quad 23.20961 \quad 23.13516 \quad 23.03835 \quad 22.94840 \quad 22.89719 \quad 22.75800 \quad 22.61791$

$22.48450 \quad 22.38208 \quad 22.30024 \quad 22.21100 \quad 22.07991 \quad 21.99245 \quad 21.85611 \quad 21.75351$

$21.68663 \quad 21.61325 \quad 21.51715 \quad 21.44288 \quad 21.35328 \quad 21.27304 \quad 21.19966 \quad 21.13856$

$21.06465 \quad 20.99723 \quad 20.90078 \quad 20.81840 \quad 20.73620 \quad 20.6173920 .50544 \quad 20.40231$

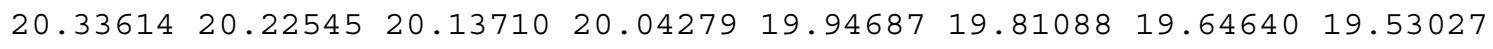

$\begin{array}{lllllllll}19.46463 & 19.33372 & 19.23888 & 19.10075 & 18.99201 & 18.88327 & 18.78860 & 18.67808\end{array}$ 
CLARK, ET AL.: BRACHIOPOD SPIRAL DEVIATIONS

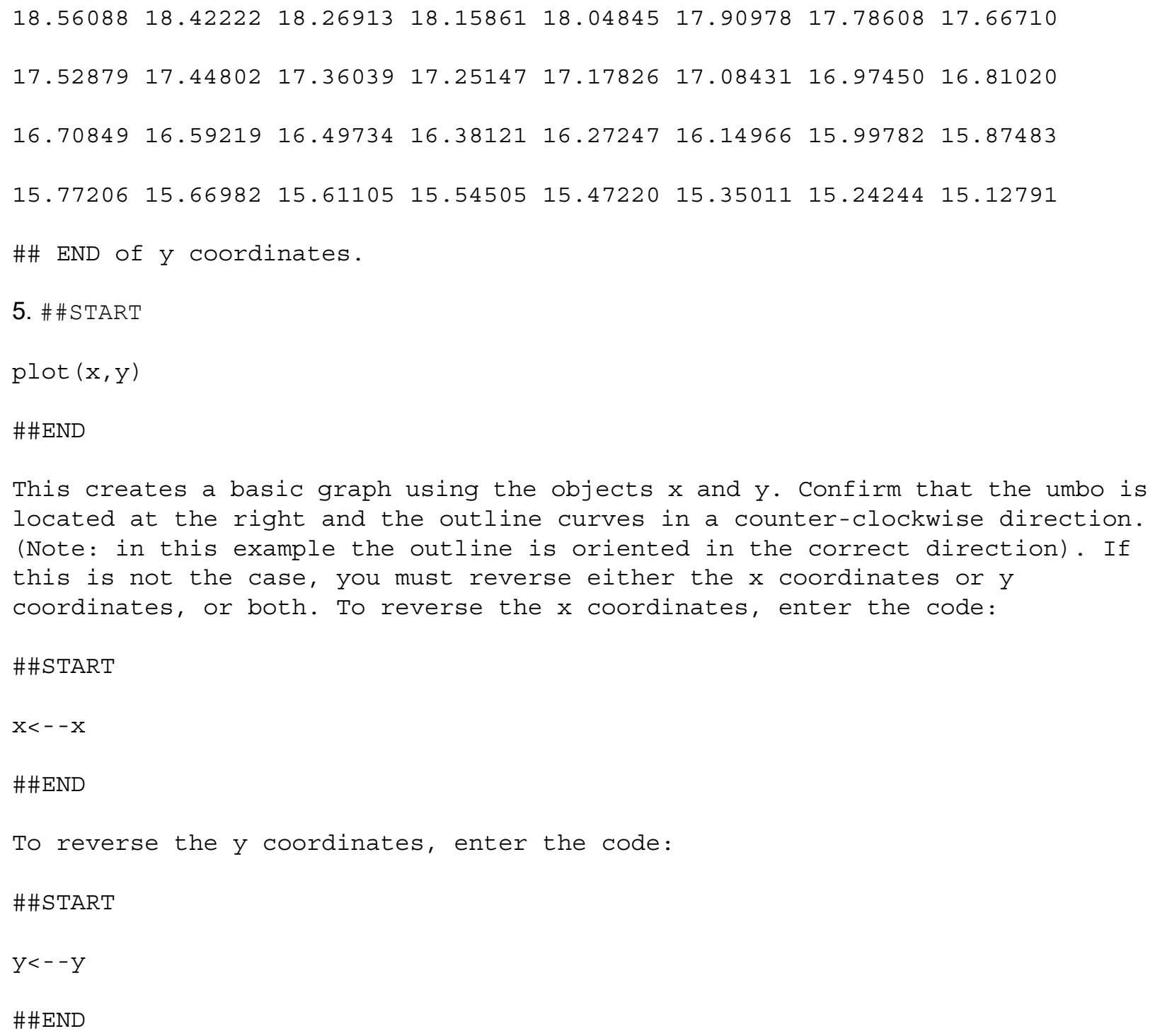




\section{APPENDIX 2.}

Instructions on generating a biological outline in $\mathrm{R}$.

Step 1: Creating a scale bar

The following directions assume you have already defined the objects " $x$ " and "y" using the brachiopod dorsal valve coordinates from appendix 1. Directions are included on how to modify the following code to suit your own data. Copy and paste the following code between \#\#START and \#\#END into R, then hit enter. Descriptions of the commands follow the code itself.

\section{1. \#\#START}

require (MASS)

\#\#END

-This loads the package "MASS", which is required for future commands.

2. \#\#START

eqscplot $(\mathrm{x}, \mathrm{y}$, axes $=$ FALSE)

\#\#END

-This plots a basic outline of the valve using equal units on each coordinate axis. No scale bar is shown with this plot; it is just a quick confirmation on whether the outline appears correct.

3. \#\#START

$\operatorname{axis}($ side $=1$, line $=-8)$

\#\#END

-This creates a default scale bar. "side=1" means that the scale bar is oriented parallel to the x-axis. This can be changed to "side =2", which orients the scale bar parallel to the y-axis. "line= 8 " is the spatial placement of the scale bar relative to the x-axis. Decreasing this number moves the scale bar up and increasing this number moves it down.

-Now that you know where the scale bar should be placed, you can edit the length and labels. Exit the graphics window, and enter the following four lines of code into the command window. The following code assumes you are using the brachiopod dorsal valve data from Appendix 1.

4. \#\#START

eqscplot ( $x, y$, axes = FALSE )

$\operatorname{axis}(1$, at $=c(25,35)$, labels $=c(" 0 \mathrm{~mm} ", " 10 \mathrm{~mm} ")$, tck $=0.02,1$ ine $=-8)$

$\operatorname{axis}(\operatorname{side}=1, a t=30$, labels $=F$, tck $=0.016$, line $=-8$ ) 
$\operatorname{axis}(1$, at $=\operatorname{seq}(25,35,1)$, labels $=F, \operatorname{tck}=0.009$, line $=-8)$

\#\#END

-The first line of code plots the biological outline of the brachiopod dorsal valve.

- The second line of code adds length, horizontal placement, and labels to the scale bar. "at $=c(25,35)$ " means that the scale bar will extend from $\mathrm{x}=25$ to $\mathrm{x}=35$. In this case, the scale bar will be 10 units long and should be labeled accordingly. "labels $=\mathrm{c}$ ("0 $\mathrm{mm} ", " 10 \mathrm{~mm}$ ")" labels the tick marks at the ends of the scale bar. At $\mathrm{x}=25$, the scale bar label is "0 mm", and at $\mathrm{x}=35$, the scale bar label is "10 mm". You can change these numbers to suit your own scale bar units. "tck=.02" creates a tick mark that extends in the upwards direction because it is positive. To make it extend downwards instead of upwards, make the value negative instead of positive. To increase the length of this tick mark, increase the magnitude of the value listed after "tck= ".

- The third line of code creates a tick mark halfway through the scale bar because in this example, $\mathrm{x}=30$ is the point midway between 25 and 35. "tck=.016" creates a tick mark that extends in the upwards direction and is shorter than the end tick marks. If you do not want a halfway tick mark on your scale bar, delete this line of code.

-It is important that the number you used for the line placement of the scale bar ("line $=-8 "$ ) is the same as the line placement of the tick marks so they overlap each other.

- The last line of code creates minor tick marks at every unit.

"at=seq $(25,35,1)$ " means that the ticks will be placed over the span of $x=25$ to $\mathrm{x}=35$, with 1 unit of space in between ticks. "tck=0.009" means that the tick marks will extend upwards and they will be shorter than the end and halfway tick marks.

- It is important to save the scale bar code you just determined in a document so that it is easily accessible in step 2 .

Step 2: Making a biological outline with a scale

Copy and paste the following code between \#\#START and \#\#END into $R$, then hit enter.

\section{1. \#\#START}

specimen.df <- data.frame $(x, y)$

\#\#END

-This combines the two objects " $x$ " and " $Y$ " into a single data frame.

2. \#\#START

z.df $<-$ specimen.df 
\#\#END

-This creates a copy of the data and saves it under the name "z.df" in case a mistake is made.

3. \#\# START

$\operatorname{dev} \cdot \operatorname{new}()$

\#\#END

-This creates a new graphic window.

4. \#\#START

eqscplot ( z.df\$x, z.df\$y, type="p", pch=16, cex=0.3, col=2, xlab=" ", ylab=" ", axes=F )

\#\#END

-This creates a plot using the data frame $z$.df. " $z$.df\$x" means that the $x$ values from the data frame "z.df" are being used in the plot. "z.df\$Y" means that the y values from the data frame "z.df" are being used in the plot. "pch=16" creates data points that are solid dots. Altering the value after "pch =" changes the style of data points (e.g., squares, diamonds, open circles). "cex=0.3" indicates the size of these data points. Increasing this value increases the size of the data points and vice versa. "col=2" indicates the color of the data points (e.g., $1=\mathrm{black}, 2=$ red, $3=$ green, $4=\mathrm{blue}$ ). "xlab="" and "ylab="" means that labels on the $\mathrm{x}$ and $\mathrm{y}$ axes are absent. "axes $=F$ " makes the $\mathrm{x}$ and $\mathrm{y}$ axes lines disappear completely.

-Now, you should have a biological outline with no labels or axes.

5. The next step is to add a scale bar to the biological outline. If you are working with the brachiopod example coordinates from appendix 1, select, copy and paste the following commands into R. The following code was determined in step 1 .

\#\#START

$\operatorname{axis}(1$, at $=c(25,35)$, labels $=c(" 0 \mathrm{~mm} ", " 10 \mathrm{~mm} ")$, tck $=0.02,1$ ine $=-8)$

$\operatorname{axis}(\operatorname{side}=1, a t=30$, labels $=F$, tck $=0.016$, line=-8)

$\operatorname{axis}(1$, at $=\operatorname{seq}(25,35,1)$, labels $=F$, tck $=0.009$, line $=-8)$

\#\#END

-Now, you should have a biological outline with a correct scale bar. 


\section{APPENDIX 3.}

$\mathrm{R}$ code necessary to create spiral deviation graphs.

Acquiring spiral deviations requires the function, fit.any.spirals, that in turn uses up to seven other functions. All eight functions are provided below. Select, copy and paste the functions listed in between \#\#START and \#\#END into your R session. Appendix 4 shows how to use these functions on example coordinate data. When exiting $R$, save the session so the functions are retained in your designated workspace.

\#\#START

start.angle <- function (xc, yc, ul, v1)

\{

start.theta <- $\operatorname{atan}(\operatorname{abs}((y c-v 1)) / \operatorname{abs}(x c-u 1))$

\# now check the starting quadrant of outline

if $(\mathrm{xc}-\mathrm{ul}<0 \& \& \mathrm{yc}-\mathrm{v} 1>0)$ start.theta $<-\mathrm{pi}-$ start.theta else

if $(\mathrm{xC}-\mathrm{u} 1<0 \& \& \mathrm{yC}-\mathrm{v} 1<0)$

start.theta $<-p i+$ start.theta

else if $(x c-u 1>0 \& \& y c-v 1<0)$

start.theta $<-2 *$ pi - start.theta

\# otherwise retain the first quadrant as the start of outline

return (start. theta)

\}

\#\# end of function to calculate the angle from given location to the first outline coordinate

cumulative.angle.fen $<-$ function ( $\mathrm{x}, \mathrm{y}, \mathrm{u}, \mathrm{v}$ )

\{

\# accumulates sequential angle between coordinates ( $\mathrm{x}, \mathrm{y})$ about an axis location $(u, y)$

\#

$$
\begin{aligned}
& \mathrm{xy} \cdot r<-\operatorname{sqrt}\left((\mathrm{x}-\mathrm{u})^{\wedge} 2+(\mathrm{y}-\mathrm{v})^{\wedge} 2\right) \\
& \mathrm{x} \cdot \text { unit }<-(\mathrm{x}-\mathrm{u}) / \mathrm{xy} \cdot \mathrm{r} \# \text { unit vector in } \mathrm{x} \text { direction } \\
& \text { y.unit }<-(\mathrm{y}-\mathrm{v}) / \mathrm{xy} \cdot \mathrm{r} \# \text { unit vector in } \mathrm{y} \text { direction } \\
& \text { npts }<- \text { length }(\mathrm{x} . \text { unit }) \# \text { number of coordinate points }
\end{aligned}
$$




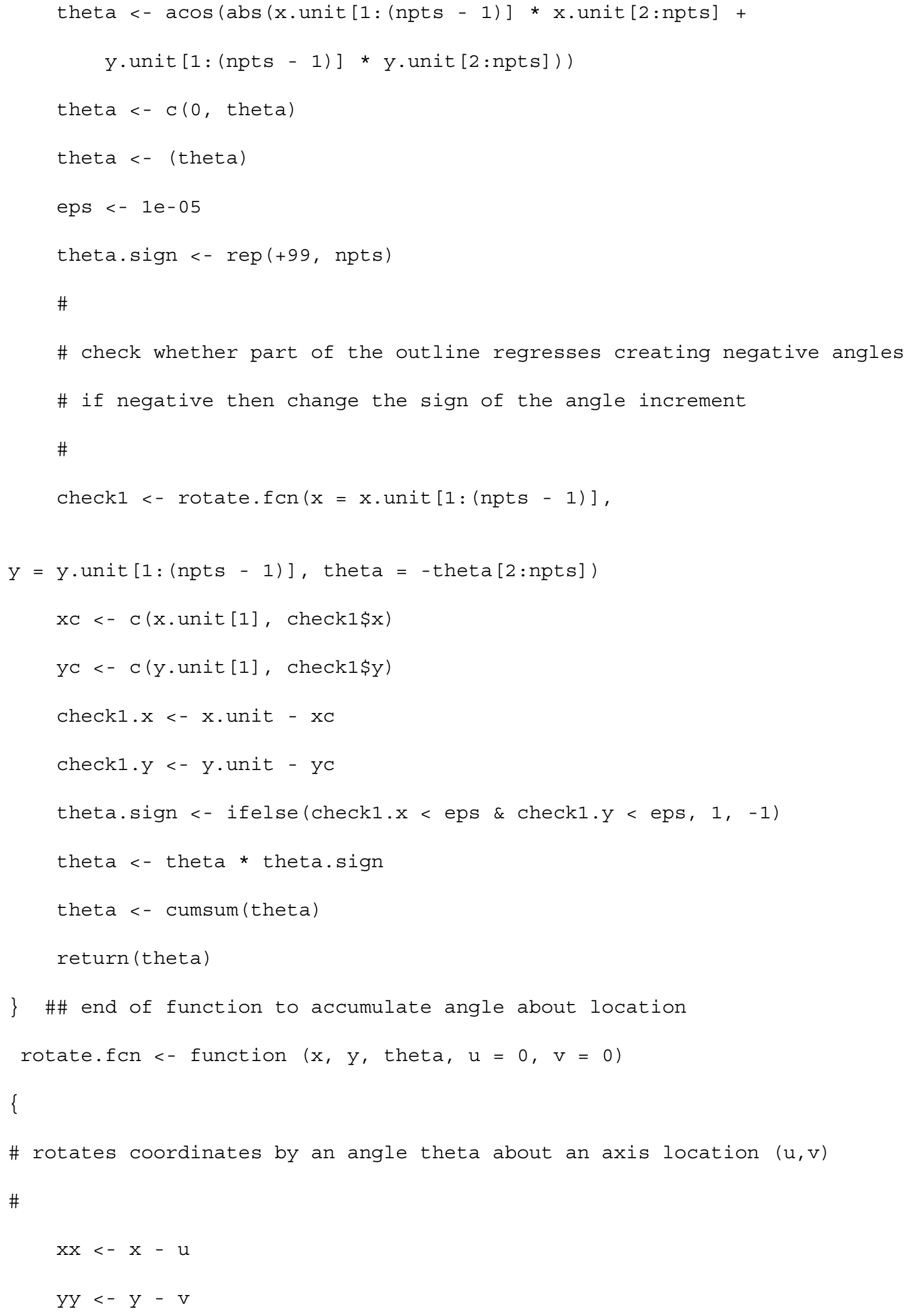


CLARK, ET AL.: BRACHIOPOD SPIRAL DEVIATIONS

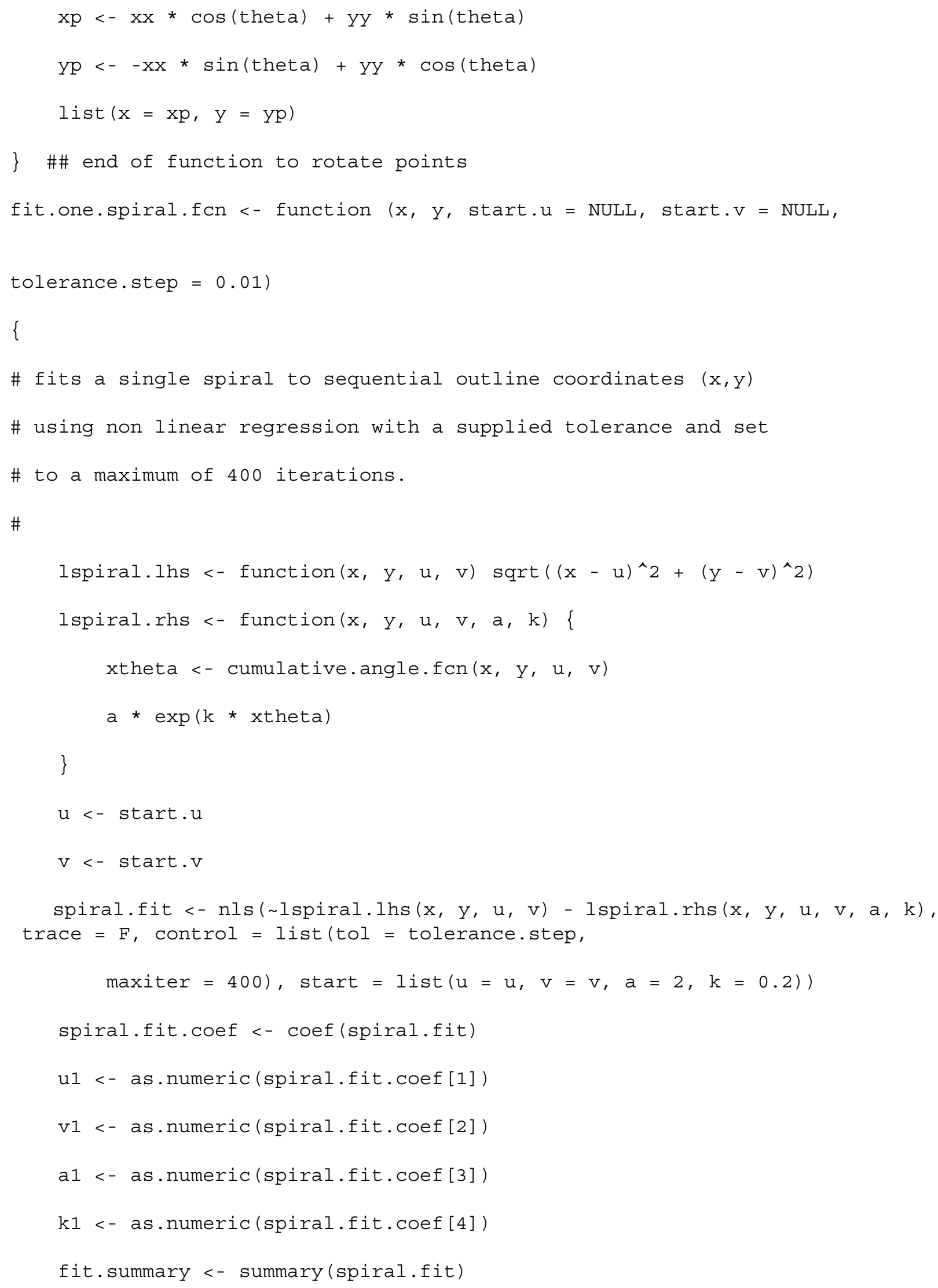




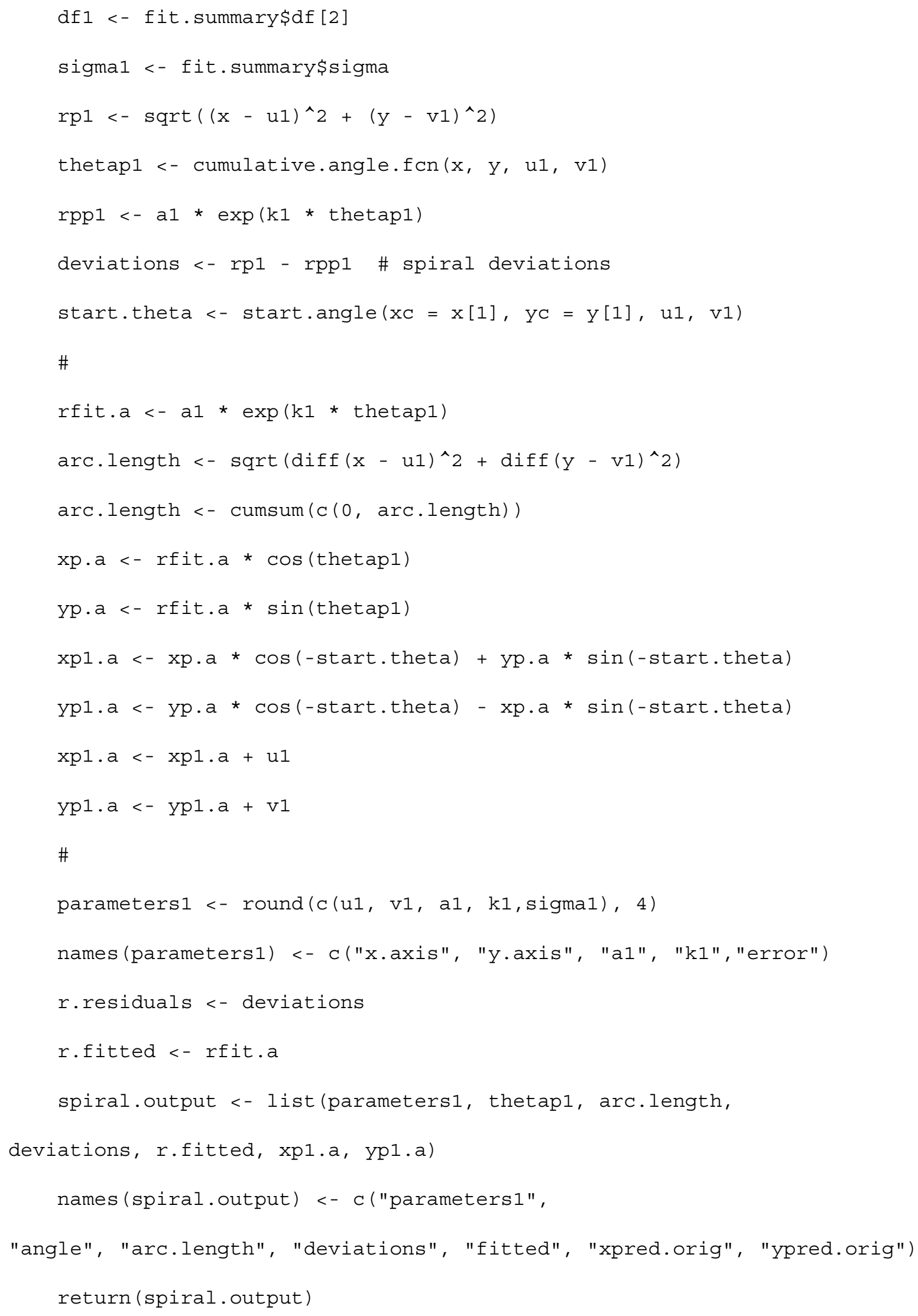


\} \#\# end of function to fit one spiral

$\#$

\#

fit.two.spiral.fen <- function ( $x, y, m=$ NULL, start.u $=$ NULL, start. $v=$ NULL, tolerance. step $=0.01$ )

\{

\# fits two spirals to sequential outline coordinates $(\mathrm{x}, \mathrm{y})$

\# the $m$ th coordinate is the user specified change in spiral

\# Nonlinear regression is used with a supplied tolerance and set

\# at a maximum of 400 iterations.

\#

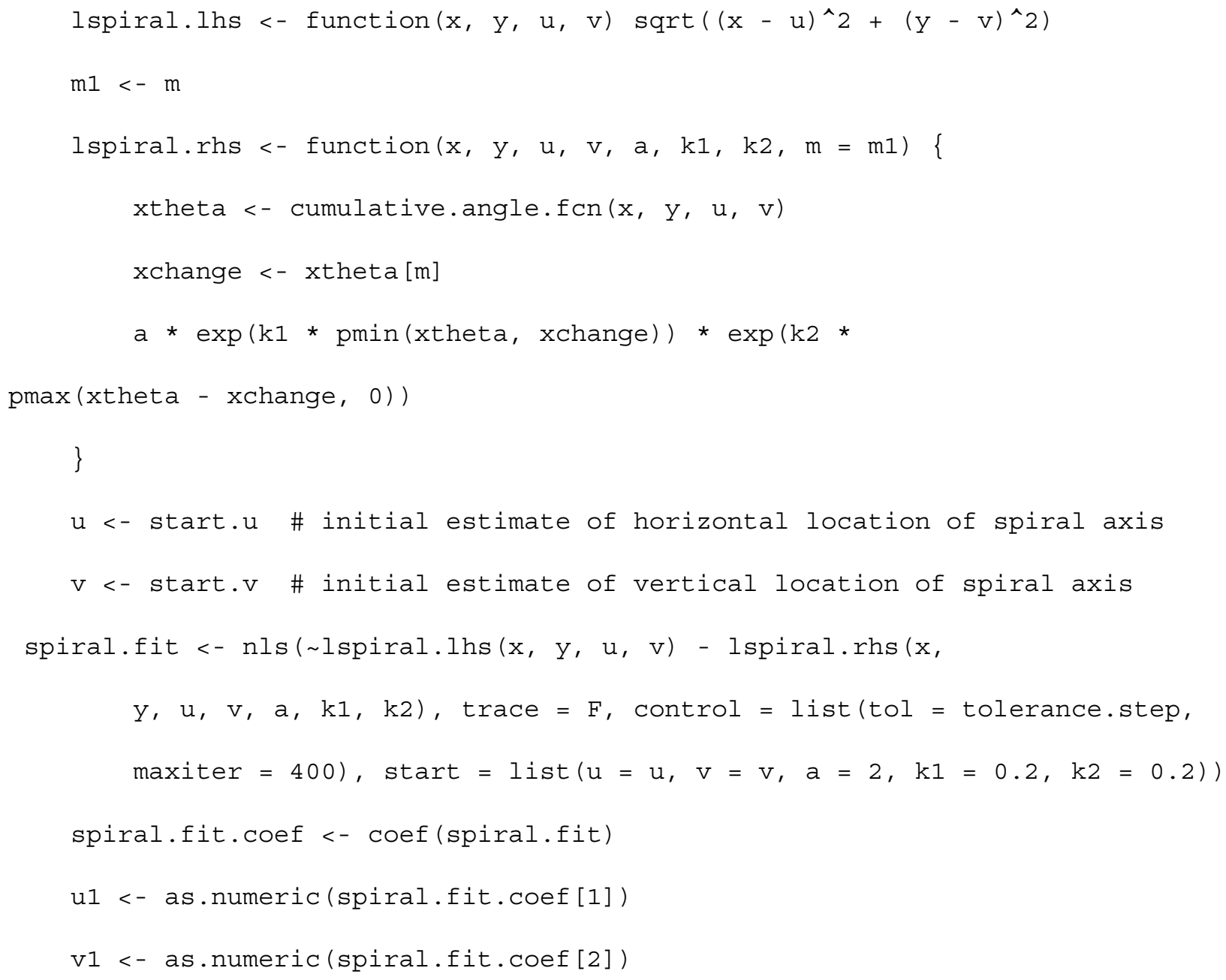




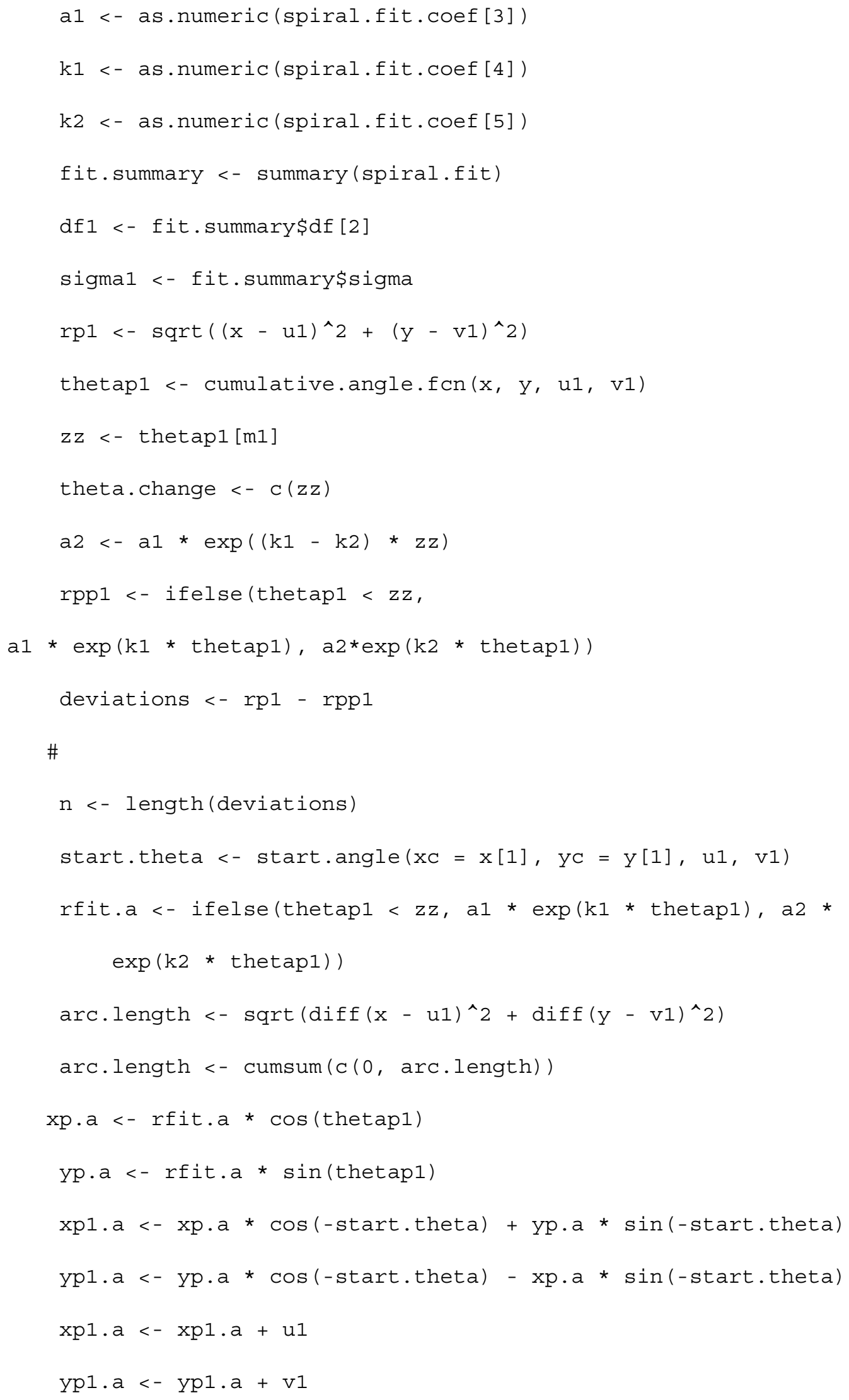




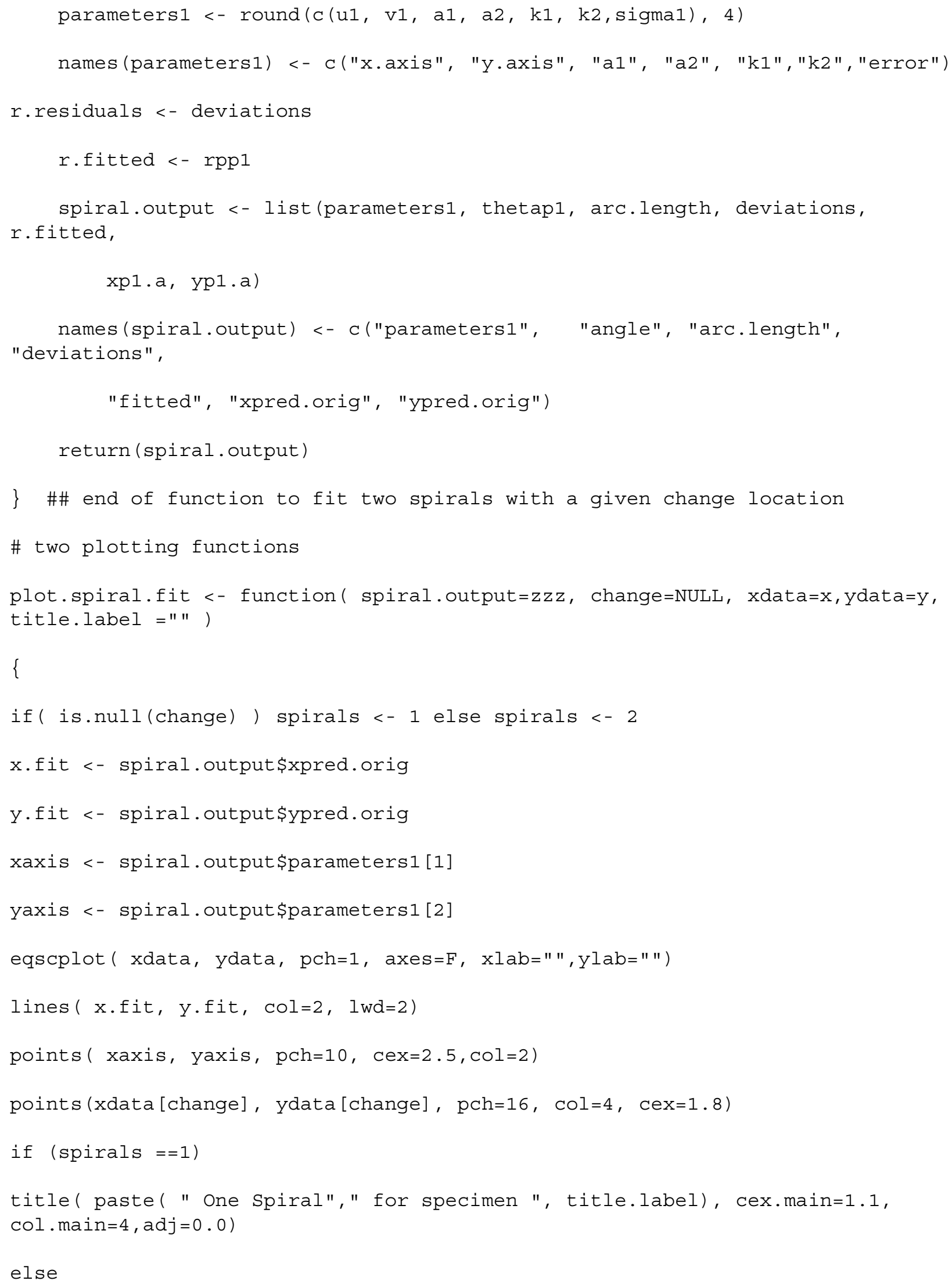




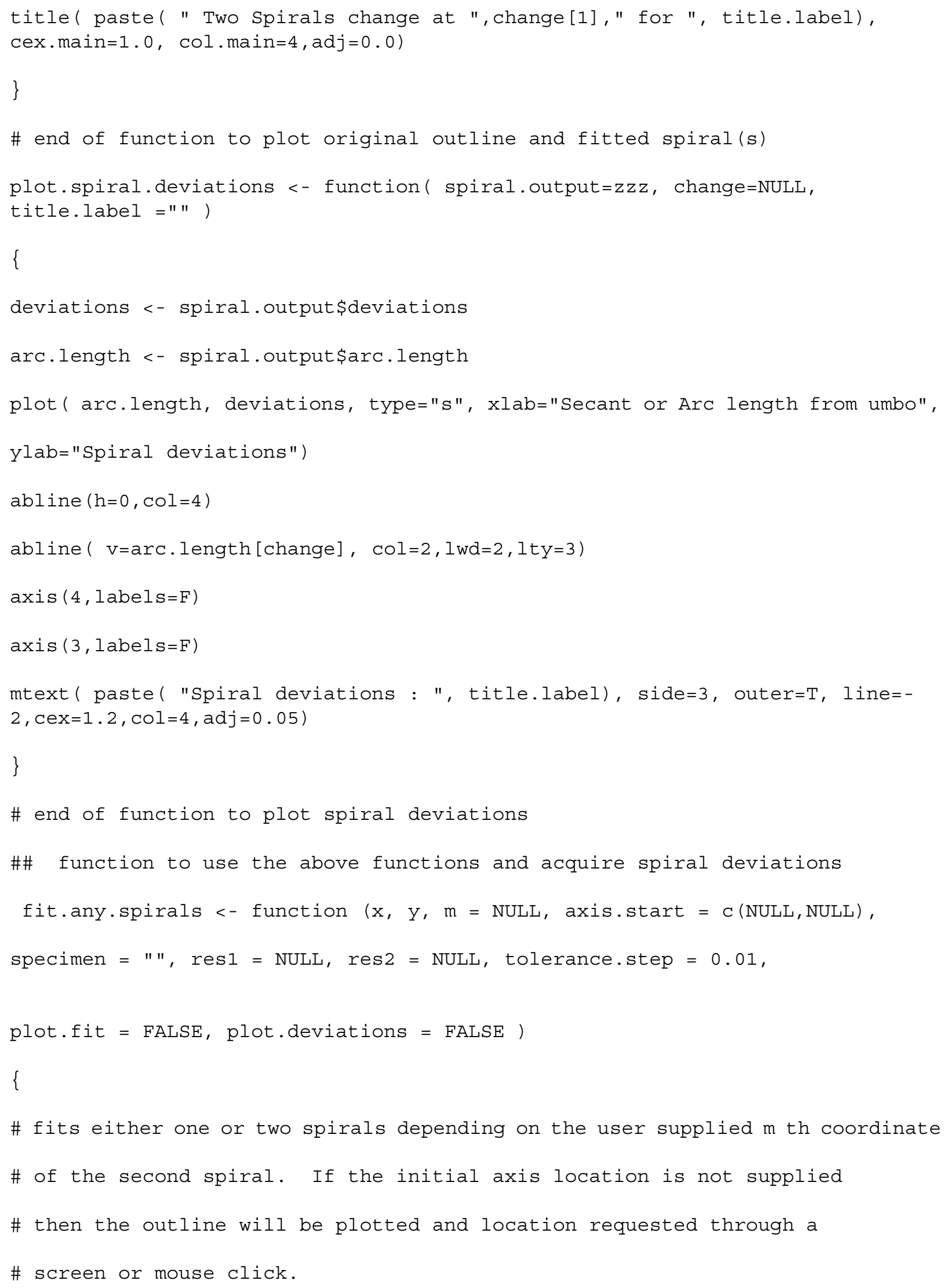




\section{CLARK, ET AL.: BRACHIOPOD SPIRAL DEVIATIONS}

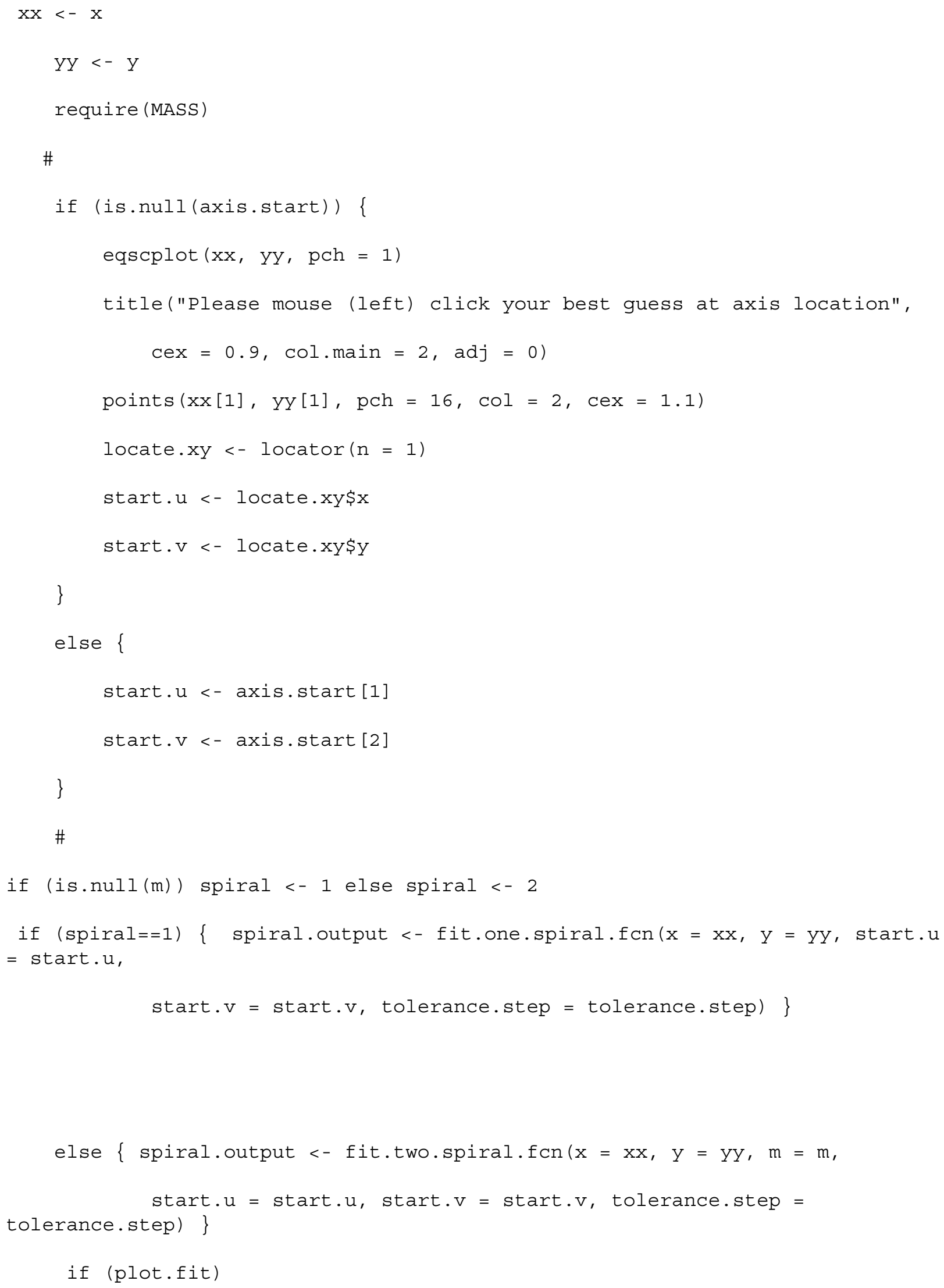




$$
\text { plot.spiral.fit (spiral.output = spiral.output, } \text { change }=\mathrm{m} \text {, }
$$$$
\text { title.label = specimen, } x \text { data }=x, \text { ydata }=y \text { ) }
$$

if (plot.deviations)

plot.spiral.deviations (spiral.output = spiral.output,

$$
\text { change }=m \text {, title.label = specimen) }
$$

return (spiral .output)

\}

\#\#END 


\section{APPENDIX 4.}

Instructions on how to use the $\mathrm{R}$ code in Appendix 3 to generate spiral deviation graphs, using either one or two spirals.

The following are directions to plotting spiral deviation graphs, with either one or two spirals. These directions assume you have worked through appendices 1-3, and are using the brachiopod shell coordinates from appendix 1. Select, copy and paste the functions listed in between \#\#START and \#\#END into your $\mathrm{R}$ session.

\section{Spiral deviations using one spiral}

1. \#\#START

example.fit<- fit.any.spirals(x,y, plot.fit=TRUE, specimen="Al, one spiral" )

\#\#END

-After entering this line of code, a cross-shaped cursor will appear and you will be asked to click the location of the spiral axis. In order to do this, imagine that you place a round coin inside the curve of the umbo so that it fits perfectly. The center of that imaginary coin is the approximate location of the spiral axis where you should click. Based on your chosen spiral axis, $R$ will choose the best location for the spiral axis. The output for this code is a spiral-fitting graph, which displays the best fit of one perfect spiral (red line) to the biological outline.

\section{2. \#\#START}

example.fit <- fit.any.spirals(x,y, plot.deviations=TRUE, specimen="A1 example")

\#\#END

-Click the approximate location of the spiral axis again. The output of this code is a spiral deviation graph, which plots spiral deviation versus growth from umbo. The blue line represents a spiral deviation of zero.

\section{3. \#\#START}

example.fit [ [1] ]

\#\#END

This code displays the spiral output, which includes x.axis, y.axis, al, k1, and error. "x.axis" and "y.axis" are the coordinates of the spiral axis location. "al" is the distance between the spiral axis and the first coordinate pair at the umbo. "kl" is the spiral parameter, which indicates the shape of the valve. Higher values are associated with flatter valves and lower values are associates with more rounded valves. "error" is an indicator of how well the perfect spiral fits the biological outline. Lower values $(<0.2)$ are preferable to higher values, and indicate a better spiral fit.

Spiral deviations using two spirals

1. \#START 
example.dorsall<- fit.any.spirals(x,y, m=108, plot.fit=TRUE, specimen="Al, two spirals" )

\#\#END

-Click the approximate location of the spiral axis. This code fits two spirals to the brachiopod outline with a second spiral start location at the 108 th point from umbo. "m=108" means that the second spiral starts at the 108 th point from the umbo. See text for discussion of where to start a second spiral. The output of this code is a spiral-fitting graph, in which the red lines are the two perfect spirals and the blue dot is the second spiral start location.

2. \#\#START

example.dorsall <- fit.any.spirals (x,y, m=108, plot.deviations=TRUE)

\#\#END

-Click the location of the spiral axis. This code creates a spiral deviation graph, which plots spiral deviation versus growth from umbo. The vertical red-dotted line represents the location where the second spiral starts.

3. \#\#START

example.dorsal1 [ [1] ]

\#\#END

-This code displays the spiral output, which includes x.axis, y.axis, a1, a2, k1, k2, and error. When using two spirals, "a" and "k" values are computed for each spiral. 


\section{APPENDIX 5.}

Spiral deviation graphs generated from the other halves of brachiopod shells shown in Figures 47.

5.1. Spiral deviation graphs generated from the corresponding halves to shells used in Figure 4 (Laqueus rubellus).

Dorsal

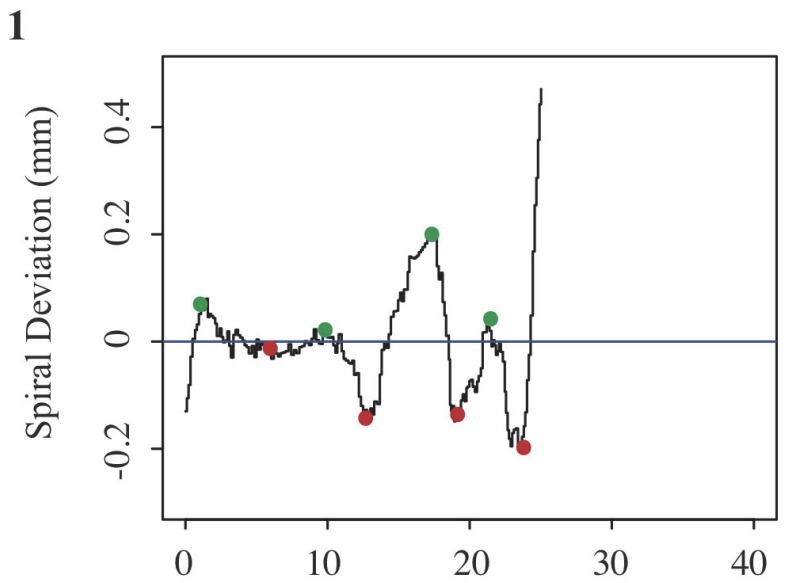

2
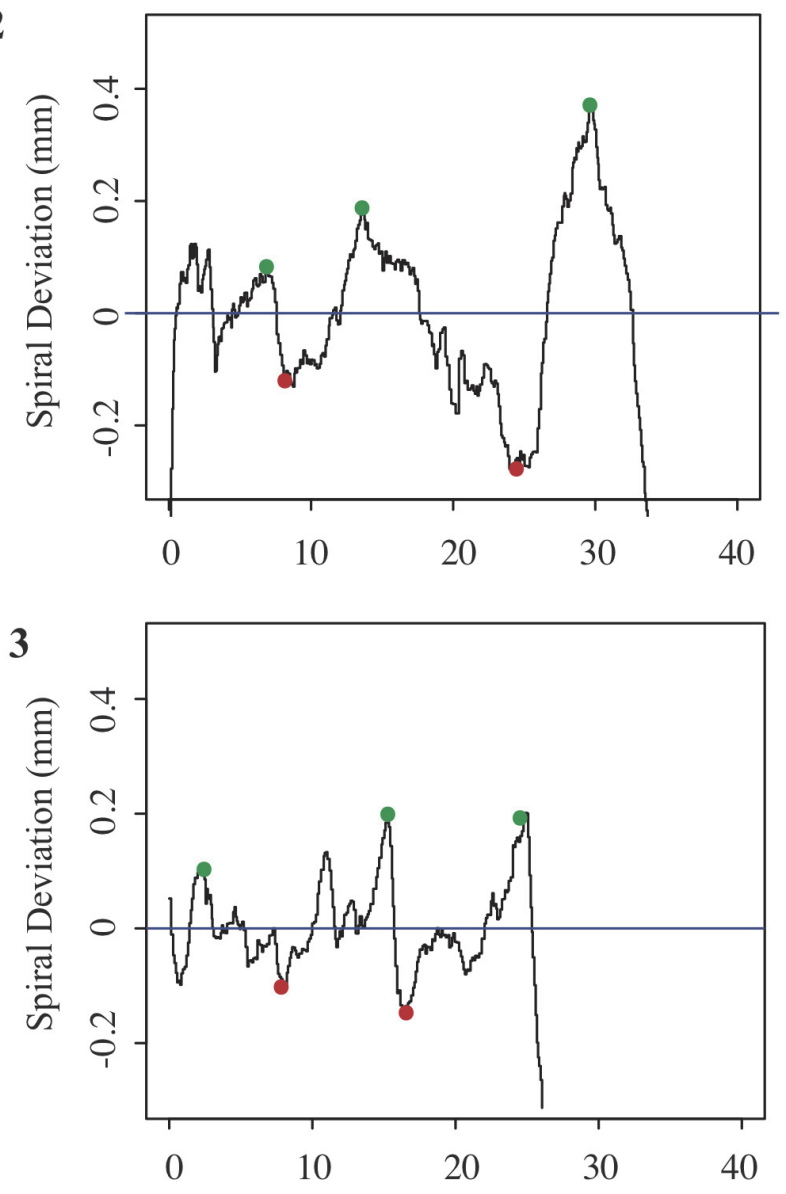

Growth from umbo (mm)
Ventral
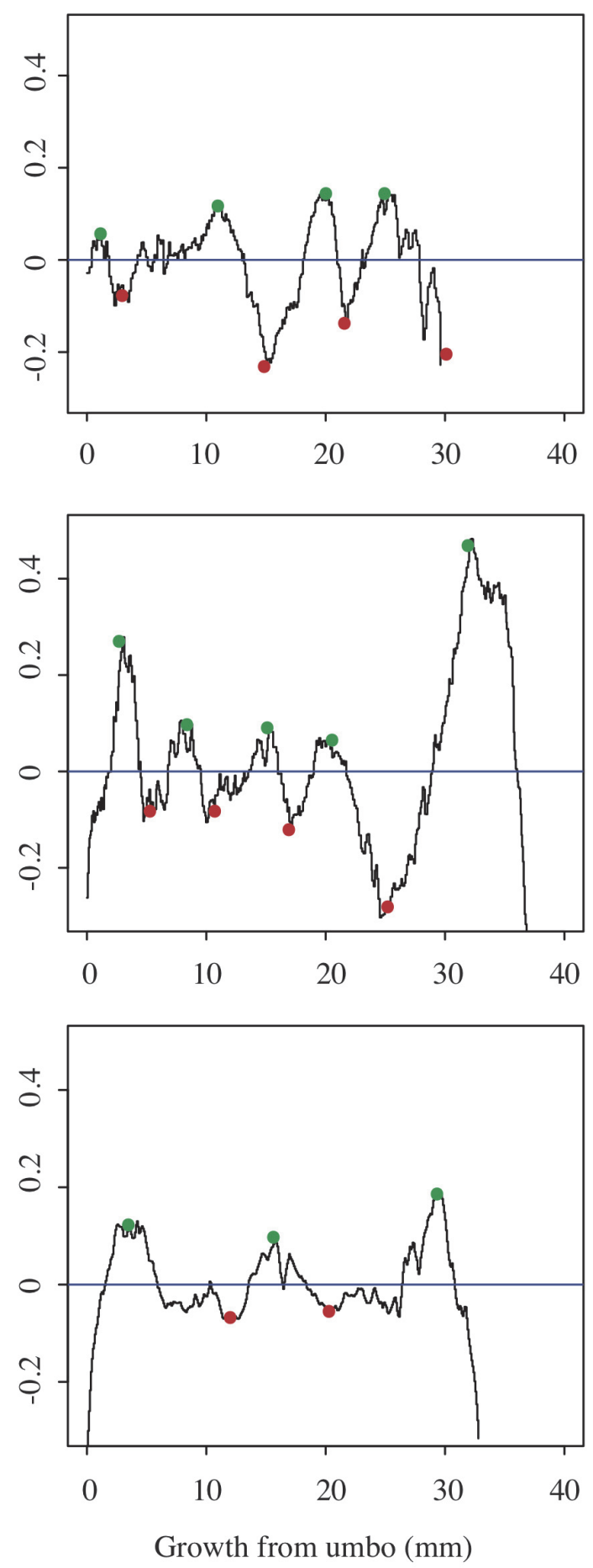
5.2 Spiral deviation graphs generated from the corresponding halves to shells used in Figure 5 (Terebratula terebratula).
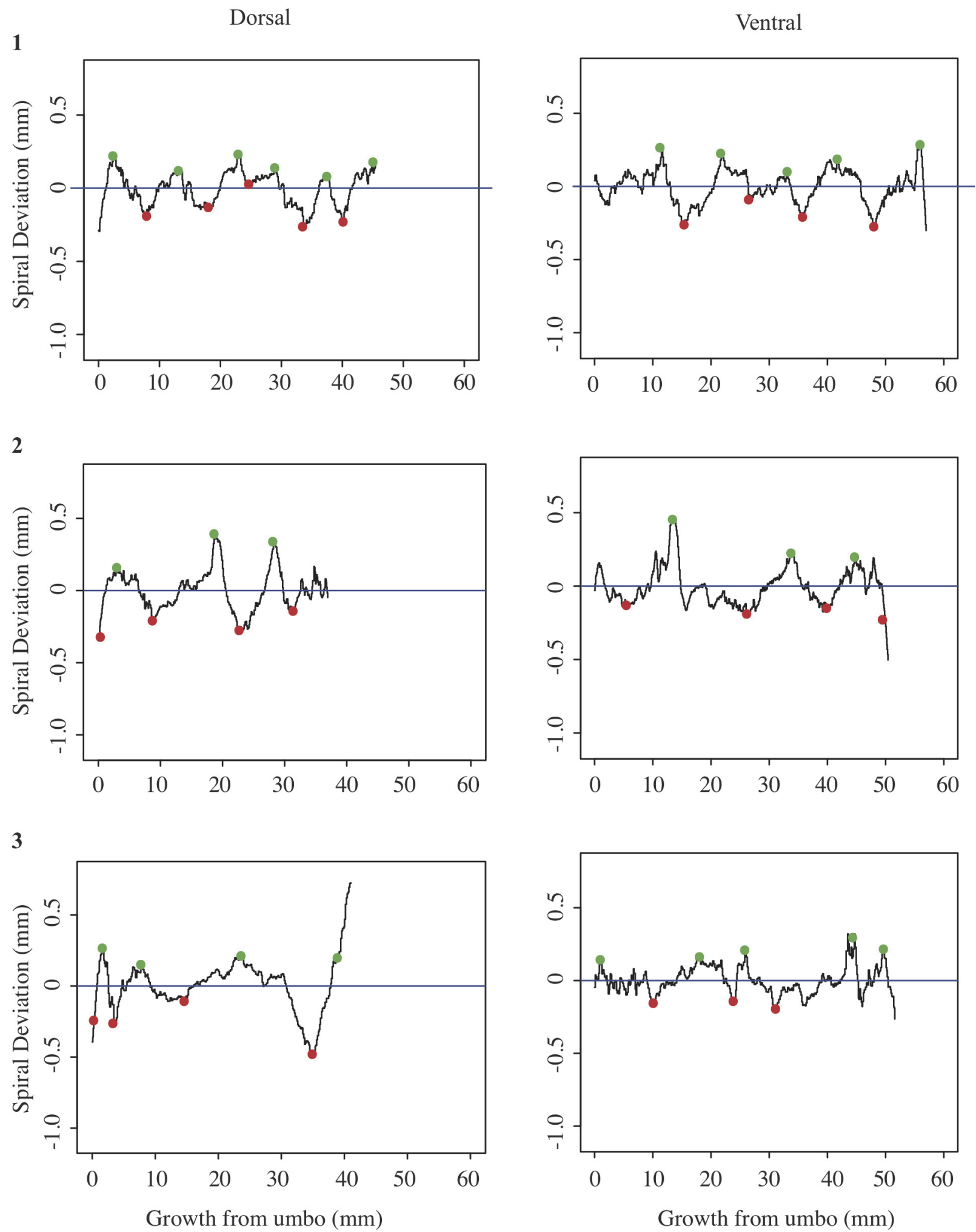
5.3 Spiral deviation graphs generated from the corresponding halves to shells used in Figure 6 (Platystrophia ponderosa).

Dorsal
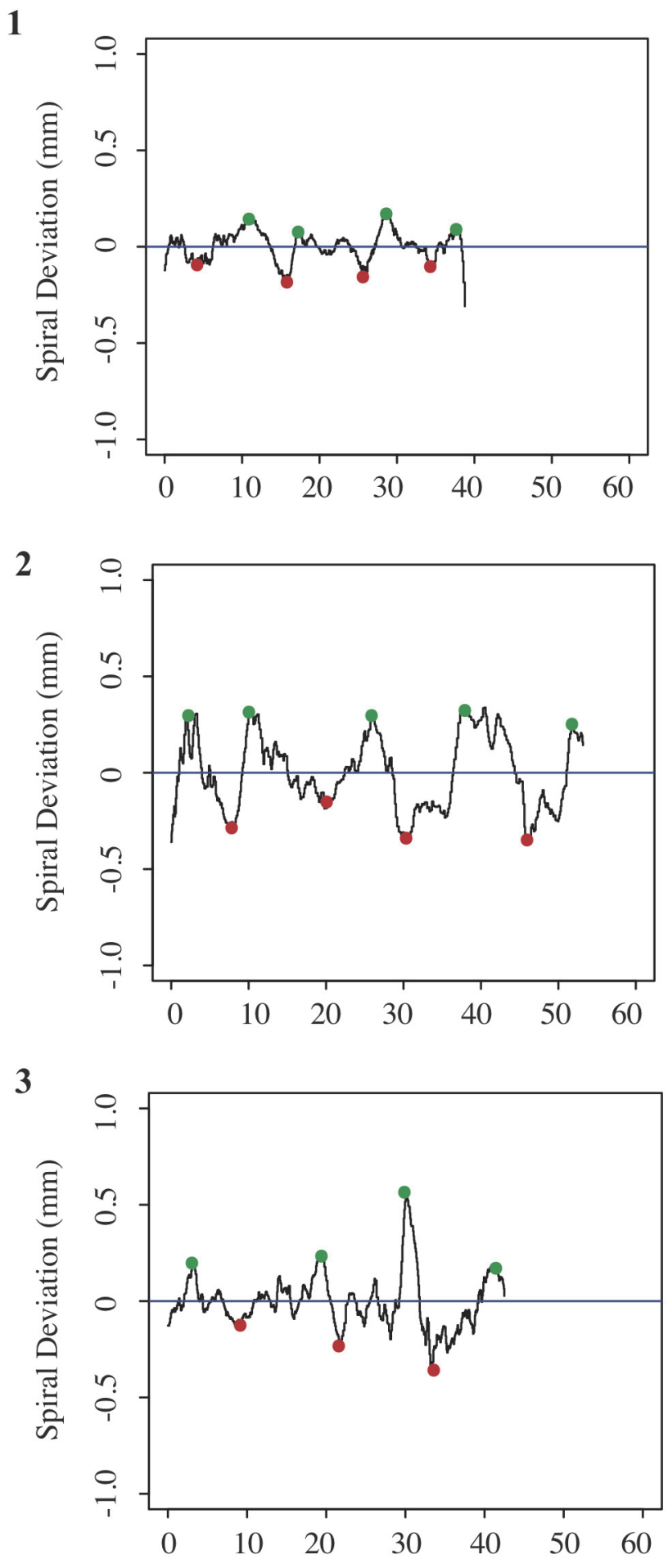

Growth from umbo (mm)
Ventral
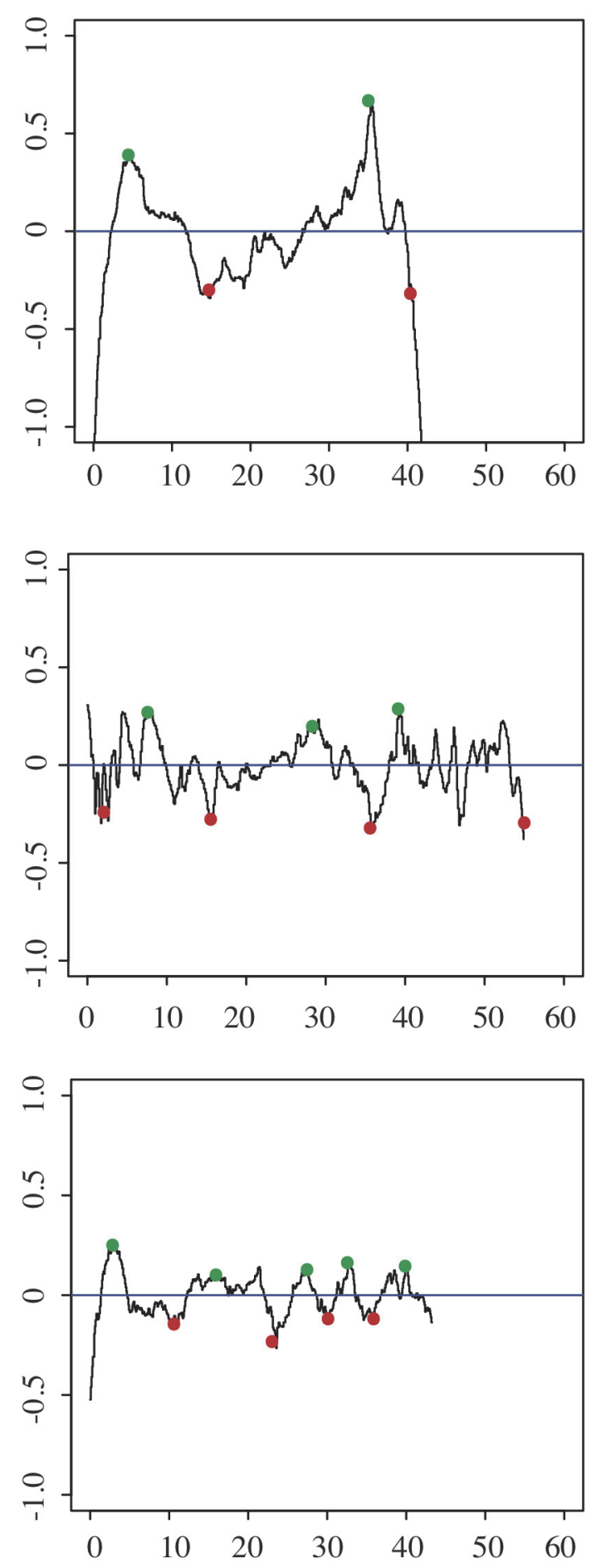

Growth from umbo (mm) 
5.4 Spiral deviation graphs generated from the corresponding halves to shells used in Figure 7 (Pseudoatrypa sp.).
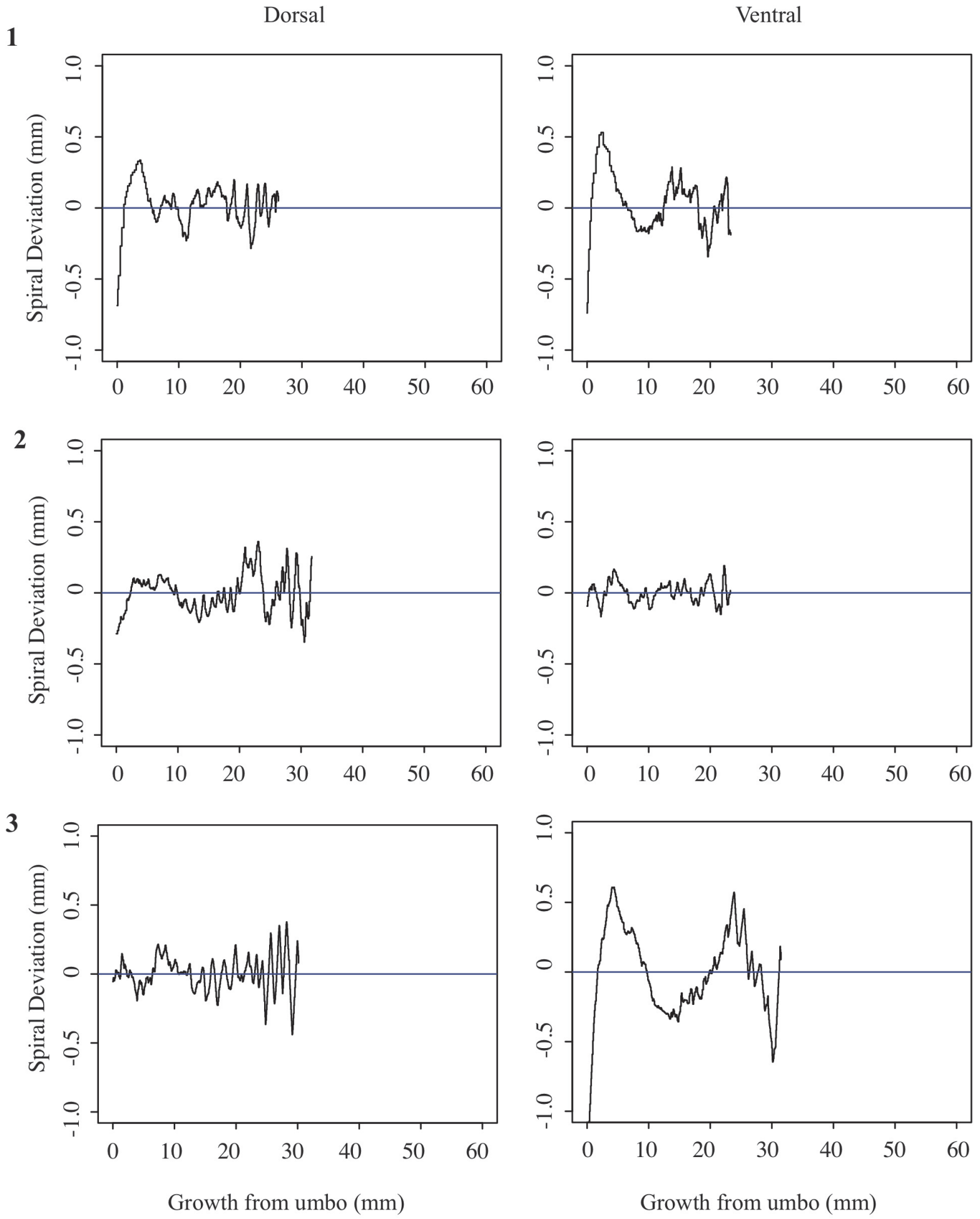